\title{
Sociedades híbridas, pueblos mixtos o mestizaje. ¿Cómo se puede percibir la población en la Huasteca potosina en el periodo colonial tardío?
}

\author{
Antonio Escobar Ohmstede \\ CIESAS, México \\ ohmstede@ciesas.edu.mx \\ Ricardo A. Fagoaga Hernández* \\ University of California, San Diego \\ rfagoaga@gmail.com
}

Recibido: Noviembre de 2013

Aprobado: Marzo de 2014

\begin{abstract}
Resumen: Basándonos en los informes eclesiásticos (seculares y regulares) y civiles, y a partir de analizar el cruce de factores como el poblamiento, las características étnicas de los pobladores y la diversidad espacial, en este artículo delineamos la manera en qué se fueron conformando los pueblos mixtos de la Huasteca potosina, y presentamos un bosquejo general en donde se ubicaron los diversos habitantes. La pervivencia de los pueblos, aun cuando los barrios se convirtieron en la referencia obligada de una casi "pureza india" frente a cabeceras y propiedades diversas o pluriétnicas, nos muestran las adaptaciones que realizaron los diversos habitantes, considerando desde un proceso de etnogénesis hasta la confrontación y expulsión de no indios de ciertas localidades. Hemos diferenciado y ubicado en su espacio a cada una de las posibles denominaciones étnicas con el fin de mostrar que lo indio no precisamente indica homogeneidad en las propias fuentes, sino importantes niveles de movilidad y diferenciación interna, ya que no era lo mismo ser identificado como pame o meco a autodefinirse como huasteco o "mexicano".
\end{abstract}

\footnotetext{
* Candidato a Doctor, Postgrado en Historia, University of California, San Diego.
}

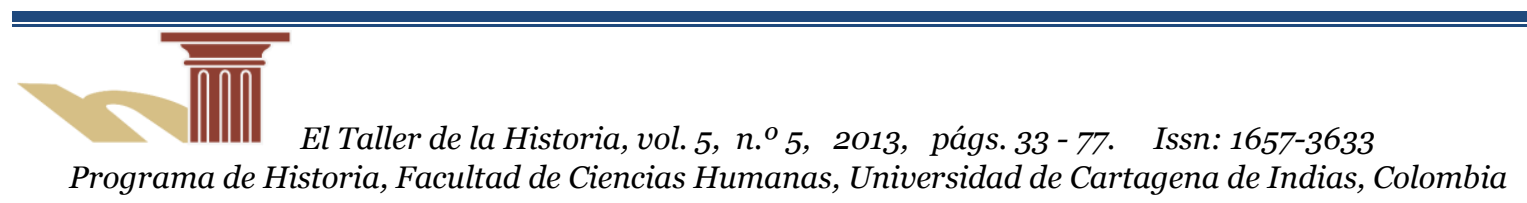


Palabras claves: Huastecas potosina, poblamiento, pueblos mixtos, mestizaje, indios, informes eclesiástico, informes civiles, siglo XVıII, Nueva España.

\title{
Hybrid entities, mixed villages or miscegenation. How do you perceive the Huasteca Potosina population in the late colonial period?
}

\begin{abstract}
Based on the ecclesiastical reports (secular and regular) and civilians, and from crossing analyze factors such as settlement, the ethnic characteristics of the people and the spatial diversity, in this article we outline the way in which they were comforming the mixed towns of the Huasteca potosina, and present a general outline where various inhabitants were located. The survival of the towns, even when neighborhoods became the obligatory reference of an almost "purity of Indian" against diverse properties or headers and multiethnic, show us the adjustments made by various inhabitants, considering from a process of ethnogenesis to confrontation and expulsion of non-Indians in certain localities. We have differentiated and we located in its space to each of the possible ethnic denominations in order to show that the Indian hardly indicates homogeneity in the sources themselves, but significant levels of mobility and internal differentiation, as it was not the same being identified as "pame" or "meco" to define themselves as "huasteco" or "Mexican".
\end{abstract}

Keywords: Huasteca Potosi, population, mixed villages, mestizaje, Indians, ecclesiastic reports, civilians reports, eighteenth century, New Spain.

\section{Presentación}

$\mathrm{E}$

l análisis sobre la calidad, tipo, cantidad y lugares donde se encontraba ubicada la población en las Huastecas durante el siglo XVIII es escasa; especialmente si observamos el caso de la llamada Huasteca potosina, no así para las denominadas como hidalguense y veracruzana, en las cuales se han realizado una serie de acercamientos a la temática a partir de los censos de 1777 y 1792, así como respecto al crecimiento de la población negra y mulata. Sin embargo, poco o nada se ha avanzado en torno a lo que ha implicado el mestizaje o en diferenciar claramente lo que implica hablar de pueblos mixtos (con porcentajes diversos de población denominada étnicamente) o si podríamos hablar de sociedades híbridas; aun cuando nos encontramos con varias disyuntivas para hablar de mestizaje, y más si lo consideramos para el siglo XVIII o para el siglo XIX en que fue visto como una categoría racial y posteriormente como una parte de la conformación de la nación. 
Respecto al espacio social que se considera en este artículo, no se puede delimitar exactamente a la Huasteca potosina, y en sí a todas las Huastecas, como se ha intentado en las décadas recientes; ya que lo que se analizará corresponde a las jurisdicciones políticas coloniales de Rioverde, Villa del Maíz y Villa de Valles, lo que abarcaba un poco más de la mitad del actual estado de San Luis Potosí (ubicado al noreste de México), y más allá de lo estimado como la "región huasteca". Una primera aclaración va en el sentido de que consideramos que los actores sociales interactúan en espacios paulatinamente definidos por ellos mismos y por las actividades sociales, culturales, políticas y económicas que desarrollan, incluso por la naturaleza que los rodea, así como en la manera en que se fueron conformando las estructuras agrarias, misionales, comerciales y políticas, por lo que "la región huasteca" queda como parte de un escenario en el que se mueven más allá de ella los individuos. Los estudios arqueológicos muestran algunas características geológicas de las localidades de Villa de los Valles y Tamuín, y de la parte norte, de las llanuras de la Huasteca. Pero las características más tardías, para la Colonia, son todavía desconocidas.

Lo que nos interesa presentar es la manera en que se conformó la población, los lugares donde se asentaron y los factores endógenos y exógenos que llevó a cambios y transformaciones de los diversos sectores socio-étnicos que estuvieron asentados en una zona considerada como de "frontera", así como dejar plasmado los procesos de cambios poblacionales que se dieron. Nos gustaría resaltar que la propia indefinición del espacio social estudiado, así como las localidades no pueden ser delimitados por "fronteras" (en términos de una demarcación precisa), como jurisdicciones políticas y religiosas, sino que se encuentran abarcando territorios sin límites exactos, y a veces ni conocidos por los propios actores. Los individuos ubicados en dicho espacio se encuentran dispersos y los lugares centrales (poblados cabecera, cascos de haciendas, etc.), cuentan con porcentajes muy reducidos de población estable, aspecto que se puede observar en muchos de los estudios que se han realizado para el periodo colonial tardío, los que demuestran que gran parte de la población asentada en zonas "rurales" los habitantes se encuentran ubicados, más allá del 50\%, en haciendas, ranchos, rancherías, barrios o sencillamente dispersos en los montes.

Un aspecto que nos gustaría resaltar, es que lo que denominaremos como Huasteca potosina contó con diversas estructuras agrarias y tipos de asentamiento, lo cual variaba la perspectiva de los informes eclesiásticos (seculares y regulares) y civiles; así tenemos, la existencia de misiones, haciendas (en algunos casos con grandes concentraciones de tierra), ranchos, rancherías, pueblos indios y mixtos, barrios y estancias, todo esto, junto con una multietnicidad y en algunos casos unietnicidad, nos lleva a presentar un mosaico complejo, donde los niveles de análisis se entrecruzan con diversas variantes, que en muchos de los casos no solamen- 
te son poblacionales, como puede ser el comercio, la creación de pueblos y misiones en haciendas, rebeliones, fenómenos naturales adversos, conformación y ajustes de espacios político-administrativos, por mencionar algunos.

Vale aclarar, que no pretendemos realizar una revisión y análisis exhaustivo en torno a los movimientos de población o de las tendencias de crecimiento y/o decrecimiento de la misma, ni llegar a una conclusión sobre las posibles implicaciones del mestizaje, pero si dejar delineado la manera en qué se fueron conformando los pueblos mixtos, así como presentar un bosquejo general en donde se ubicaron los diversos habitantes, aspecto que permitirá contar con los elementos necesarios para observar en el futuro la conformación de los ayuntamientos, el papel del comercio y del intercambio de mercancías, la aparición de pueblos y misiones dentro de propiedades privadas, etc., además, de tener un botón de muestra sobre una temática poco trabajada por la historiografía sobre las Huastecas. ${ }^{1}$

\section{Un acercamiento al tipo de fuentes}

El interés por entender el desarrollo y las posibles contracciones poblacionales durante el periodo colonial se iniciaron propiamente en la década de los años setenta del siglo xx, lo que no quiere decir que no haya existido un interés por conocer cuáles eran los componentes sociales y por sexo que formaban las sociedades en diversos momentos históricos, reflejado en la necesidad de parte de las autoridades españolas y mexicanas de saber cómo se distribuían los habitantes en el territorio por ellos conocido. Los trabajos de Woodrom Borah y Sherburne Cook fueron los que marcaron la necesidad de profundizar en el conocimiento y análisis de la composición socio-étnica del periodo colonial. ${ }^{2}$ Las propuestas de Borah y Cook han sido parcialmente seguidas, en el sentido de observar como evolucionaban los miembros de una sociedad y el entorno de estos, lo que no ha evitado que en la historiografía dedicada al análisis colonial se hayan incluido análisis sobre el tipo de habitantes con que contaba alguna región, área o ciudad.

\footnotetext{
${ }^{1}$ Véase Antonio Escobar Ohmstede y Luz Carregha, "Introducción. El siglo XIX en las Huastecas. Breve balance sobre la 'región' y temas en la historiografía”, en Antonio Escobar Ohmstede y Luz Carregha (coords.), El siglo XIX en las Huastecas, México, CIESAS/COLSAN, 2002, pp.13-39; Antonio Escobar Ohmstede, "Insurgencia y ayuntamientos en las Huastecas", en Pilar Gonzalvo y Andrés Lira (coords.), México, 18o8-1821. Las ideas y los hombres, México, COLMEX, 2014, pp.133-177.

${ }^{2}$ Sherburne F. Cook, "La población de México en 1793", en Elsa Malvido y Miguel Ángel Cuenya (comp.), Demografía histórica de México: siglos XVI- XIX, México, Instituto Mora/Universidad Autónoma Metropolitana, 1993, pp.141-159; Sherburne F. Cook y Woodrow Borah, Ensayos sobre historia de la población: México y el Caribe, t. I, México, Siglo XXI, 1977.
} 
Los estudios centrados en lo que se ha denominado demografía histórica, se han enfocado sobre la manera en que se relacionaron los individuos biológica y culturalmente, sobre tasas de mortalidad, natalidad, matrimonios entre miembros de una misma "calidad racial" o interétnicos, así como los niveles de "masculinidad" o "femeneidad". Lo anterior permite tener una visión sobre el desarrollo de la población en algunas regiones de la Nueva España, principalmente de aquellas en que se encuentran materiales que permiten ver procesos históricos de más o menos larga duración. ${ }^{3}$ El que los estudios sobre estructura familiar, composición socio-étnica y socioeconómica, así como entender los procesos de conformación de los pueblos mixtos en el periodo colonial tardío hayan tenido poca continuidad y atención se debe al tipo de fuentes que es necesario consultar, aspecto que poco se ha desarrollado para los primeros años del México republicano. ${ }^{4} \mathrm{Si}$ bien contamos con censos y padrones civiles y eclesiásticos, éstos son esporádicos y en ocasiones cubren parcialmente los requisitos solicitados por la Corona o autoridades novohispanas, y en muchos casos pueden ser contradictorios, posfechados o dejan amplias dudas sobre como caracterizar a la población en términos de "raza" 5 Situación que se vuelve mucho más compleja después de 1821, cuando de un "plumazo" se borran las "barreras" étnicas declarando a todos los nacidos en suelo mexicano como iguales; aun cuando en las parroquias o en informes civiles se siga hablando de los "antes llamados indios". Sin embargo, y aunque se siguen elaborando censos, las "nuevas" autoridades obligan a que se elimine la categoría racial de los concentrados estadísticos.

Con base en lo anterior, es que el investigador interesado en conocer los ritmos de ascenso o descenso de la población, en ocasiones, debe combinar fuentes provenientes de otros periodos o autoridades, sean civiles, eclesiásticas o militares, lo que da incongruencias sobre el número de personas que cobijaban las localidades

${ }^{3}$ Véase entre algunos, los que se encuentran en Carmen Blázquez, Carlos Contreras y Sonia Pérez Toledo (coords.), Población y estructura urbana en México, siglos XVIII y XIX, México, Instituto Mora/Universidad Veracruzana/Universidad Autónoma Metropolitana, 1996, y Manuel Miño Grijalva, Manuel (coord.), La población de la ciudad de México en 179o: variables económicas y demográficas de una controversia, México, INEGI/COLMEX, 2002.

\footnotetext{
${ }^{4}$ Una evaluación de los estudios que se han realizado en torno a la demografía histórica de la Nueva España, véase Pedro Pérez Herrero, "Evolución demográfica y estructura familias en México (17301850)", en Familias novohispanas. Siglos XVI al XIX. Seminario de Historia de la Familia, México, COLMEX, 1994, pp.345-372.

${ }^{5}$ Sobre algunas de las razones y motivos por los cuales se realizaban informes civiles y eclesiásticos durante el periodo colonial novohispano, consúltese Lourdes Romero Navarrete y Felipe Echenique, Relaciones geográficas de 1792, México, INAH, 1995. Sobre los diversos informes que realizaron las autoridades novohispanas para las Huastecas, véase Juan Manuel Pérez Zevallos, "Las Visitas de la Huasteca (siglos XVI-XVIII)", en Jesús Ruvalcaba Mercado (coord.), Nuevos aportes al conocimiento de la Huasteca, México, CIESAS/CIHSLP/CEMCA/IPN/UACH/INI, 1998, pp.95-122.
} 
urbanas (pueblos, misiones) o rurales (ranchos, haciendas o rancherías); además que entre una década y otra aparecían y desaparecían localidades, y en algunas no variaban en décadas. Asimismo, el interés de cada autoridad, fuera religiosa o no, marcó las características y profundidad de los datos presentados en los informes finales. Un aspecto que debe tomarse en cuenta, sobre todo cuando se analizan padrones específicos, es que solamente puede ser considerado como una fotografía del momento en que fue elaborado. Faltaría observar el antes y después para entender las tendencias demográficas, además de conocer y explicar el entorno geográfico y económico. A la par, hay que considerar que en pocos casos contamos con series continuas de alguna localidad, aun cuando se pretenda realizar estudios sustentados en archivos parroquiales; ${ }^{6}$ asimismo, hay que tener presente las épocas o circunstancias en que la población se veía afectada, ya sea por un crecimiento poblacional o un recorte de territorio de cualquier índole (pérdida de tierras comunales por la expansión de haciendas o reducción de áreas de cultivo por rompimientos y alteraciones ecológicas).

Por otro lado, es conveniente observar el impacto de las epidemias y pandemias, así como las "secas", heladas o nevadas extemporáneas, entre cuyos efectos está la destrucción de las siembras y la muerte de animales, lo que afecta directamente a los individuos que componen las sociedades. ${ }^{7}$ Un hecho a considerar es que las epidemias podían ocasionar la movilización de contingentes humanos, que en muchos casos no regresaban a sus lugares de origen. En otros, la movilidad de población se debió a la necesidad de los individuos de satisfacer requerimientos alimenticios y económicos (pago de tributos, obvenciones parroquiales, etc.), por lo que "se refugiaban" en propiedades privadas, a lo cual habría que diferenciar entre la migración individual y la colectiva. ${ }^{8}$ Por estas razones, es que no es posible elaborar

\footnotetext{
${ }^{6}$ Por ejemplo, Thomas Calvo y Gustavo López (coords.), Movimientos de población en el Occidente de México, México, CEMCA/COLMICH, 1988, y Robert McCaa, "Marriage, migration, and settling down: Parral (Nueva Vizcaya), 1770-1788”, en David J. Robinson, (ed.), Migration in Colonial Spanish America, Cambridge, Cambridge University Press, 1990, pp.212-237.

${ }^{7}$ Véase como ejemplos, América Molina del Villar, "Impacto de epidemias y crisis agrícola en comunidades indígenas y haciendas del México colonial, (1737-1742)", en Virginia García (coord.), Historia y desastres en América Latina, vol.I, México, LA RED/CIESAS, 1996, pp.146-166; de la misma autora, La Nueva España y el Matlazahuatl, 1736-1739, México, COLMICH/CIESAS, 2001, así como Alma García Hernández, "Alternativas ante las sequías de 1789-1810 en la Villa de Saltillo, Coahuila, México”, en Virginia García (coord.), Historia y desastres en América Latina, vol.2, México, LA RED/CIESAS, 1997, pp.148-169.

8 Por ejemplo los trabajos que contiene Familias novohispanas, y los estudios de Carlos Manuel Valdés Dávila e Ildefonso Dávila del Bosque, Los tlaxcaltecas en Coahuila, México, COLSAN/Gobierno del Estado de Tlaxcala, 1999. Sobre las posibles características de los movimien-
} 
un estudio sobre la composición poblacional de una ciudad, localidad, área o región si no se considera el entorno geográfico inmediato y su relación con la estructura agraria, política, económica o social. ${ }^{9}$

Aun con las limitantes planteadas es importante realizar estudios donde los habitantes sean los actores principales y no el telón de fondo de una investigación, lo que no demerita el que exista otro tipo de información que permita explicar el por qué se concentran o no los individuos en ciertos lugares o regiones, y si estamos hablando de sociedades multiétnicas, multiculturales $o$ de sociedades uniétnicas y uniculturales, que para el caso de la Nueva España es bastante difícil considerar un tipo de sociedad uniétnica, sobre todo cuando hay existió un constante entrecruzamiento social y biológico, principalmente durante el periodo colonial tardío, aspecto que nos lleva a la consideración de los pueblos mixtos.

Las fuentes primarias que serán utilizadas cubren un arco temporal importante; aun cuando su origen es sumamente diverso, nos permite saber las características en que fueron realizadas y tratar de cruzar la información en ciertos momentos históricos. Sin embargo, hay que considerar, que como todo documento generado, su razón de ser tenía un porqué, y proyecta la visión particular del que lo elaboraba. Asimismo, hemos intentado estructurar las fuentes a partir del origen de la misma, fuere civil o eclesiástica. Sin embargo, la crítica a la propia fuente, surge cuando la información nos permite contrastarla con otros datos e informaciones. Un aspecto a considerar, dentro de los materiales eclesiásticos, es la queja de los frailes a la pérdida de "indios de campana" de las misiones, muchos de los cuales fueron llevados, en colleras y casi en calidad de esclavos, a fundar las misiones norteñas del Nuevo Santander a mediados del siglo XVIII, aunque también se podría considerar como un tipo de movilidad "forzada". A la vez, permite observar el proceso de etnogénesis que adoptan los pames al tratar de asimilarse a los teenek y nahuas,

tos poblacionales, David J. Robinson, "Introduction: towards a typology of migration in colonial Spanish America", en R. Robinson (ed.), Migration in Colonia, pp.1-17.

${ }^{9}$ Para el caso de San Luis Potosí existen trabajos sobre las modificaciones del medio geográfico debido a la ganadería, véase Miguel Aguilar Robledo, "Ganadería, tenencia de la tierra e impacto ambiental en una región fronteriza de la Nueva España: la Jurisdicción de la Villa de Santiago de los Valles de Oxitipia, 1527-1821", en Estudios Geográficos vol.LXIX, n. ${ }^{\circ} 230$, Madrid, CSIC, 1998, pp.534. En torno a la perspectiva de la historia ambiental, Stefania Gallini, "Historia, ambiente y política: El camino de la historia ambiental en América Latina”, en Nómadas n. ${ }^{\circ} 30$, Bogotá, Universidad Central, 2009, pp.92-102. Así como a Paul S. Sutter, "The World with US: The State of American Environmental History", in The Journal of American History vol.100, n. ${ }^{\circ}$, Bloomington, Organization of American Historians, 2013, pp.94-119. 
aspecto que ya había sido resaltado por Fray Bernardino de Sahagún desde el siglo XVI. ${ }^{10}$

Un aspecto más que habrá que destacar, y que puede considerarse como una primera consideración final, es que encontramos un tipo de movilidad de población que giraba, en algunos casos, en la manera en cómo se desarrollaba la vida eclesiástica y secular, esto es, encontramos "huidas" de indios de las misiones a la sierra cuando se les obligaba a asistir a misa o no se hallaban conformes con la vida en la misión, aun cuando también se realizaba un movimiento contrario en momentos de escasez de alimentos. Otro aspecto, fue la inspección militar y evangelizadora de José de Escandón, quien se llevó a muchos indios pames del sur al norte; la tercera, era que se llevaban a los indígenas a trabajar a las haciendas de la región. La última, es considerar que se dio un crecimiento de población, así como una necesidad de mayor fuerza de trabajo en las propiedades privadas, como lo demuestra la creación de las misiones de San José de los Montes Alaquines y la Divina Pastora, ambas creadas y fortalecidas por los hacendados, con el fin de contar con mano de obra durante el siglo XVIII, y que posteriormente ascendieron a la categoría de pueblos.

\subsection{Clasificación de la información a partir de las fuentes}

Podemos encontrar en los manuscritos cuatro tipos de información útil para entender la población, su ubicación y posibles "fronteras", los que podemos entender así:

a) Geografía. Las descripciones geográficas, principalmente de los años de 1743, 1748, 1761-62, 1778 y 1792, son de las que más se puede obtener información. Incluso podríamos hacer una clasificación: 1) Paisaje. Los elementos geográficos que son distinguibles a lo largo del tiempo como son sierras, llanos, montañas y ojos de agua; 2) Clima. Principalmente, para 1743, se puede crear una cartografía por la percepción atmosférica: caliente, cálido, húmedo, frío, lo que a su vez podría explicar el tipo de asentamiento de la población de manera dispersa; 3) Asentamientos. Cada uno de los pueblos cuenta con una descripción del sitio donde está fundado: loma, llano, al lado de (río, arroyo), cumbres; 4) Vegetación. Los frutos de

\footnotetext{
${ }^{10}$ No solamente en el caso de pames que se querían parecer a teenek o nahuas, sino también en el caso de mulatos, lobos y chinos "matriculados por indios de pueblo"; aunque en este caso puede existir la variante de querer acceder a las tierras de los indios. Biblioteca Nacional (BN), Fondo Franciscano, 45/1034, ff.1-7. Esta información se la envío el custodio Miguel de Santiesteban al padre fray Andrés Picazo en torno a Valle del Maíz en 1758.
} 
cada lugar son mencionados de una forma breve, pero da elementos para conocer las variedades; y 5) Fronteras. Los asentamientos delimitan en el papel su entorno por otros asentamientos y se describen distancias entre una y otra.

b) Demografía. El número de familias e individuos da una buena idea de la cantidad de población existente en cada asentamiento. A esto, esporádicamente, se agregan características raciales, pero evita el poder realizar ciertas generalidades sobre el mestizaje.

c) Economía. A cada pueblo se agrega información productiva. En algunos casos se menciona la tecnología y la división del trabajo; en otros los tipos de semillas o animales que pueden obtenerse, y de las mercancías que circulan, esto se nota de mejor manera en las noticias estadísticas de 1826.

d) Social. Se menciona, de forma indistinta, los problemas que se tiene con la población o las quejas de los indígenas. Aquí podemos agregar que se puede crear una visión de los "naturales" por los comentarios de cada pueblo o de algún personaje que causó daño o sobresalió en algún momento.

\section{Varios escenarios, localidades y actores}

Consideramos que es esencial en el análisis de la población de la Huasteca potosina para la segunda mitad del siglo XVIII determinar las localidades o lugares dónde se encuentran los individuos y de qué tipo eran. Esto nos permite ubicar, junto con los escenarios, los espacios que ocupaban los actores, el número aproximado de habitantes, las características étnicas y su distinción a partir de las relaciones sociales o de poder con otros grupos, así como sondear la existencia de los pueblos mixtos a fines del periodo colonial tardío.

Como en otras regiones de la Nueva España no podemos afirmar que los individuos solamente se encontraban asentados en sitios como pueblos, misiones, haciendas, ranchos, estancias, barrios o tlaxicales, y con esa facilidad localizarlos. ${ }^{11}$

\footnotetext{
${ }^{11}$ Para Yucatán: Nancy M., Farris, La sociedad maya bajo el dominio colonial. La empresa colectiva de la supervivencia, Madrid, Alianza Ed., 1992, pp.329-348; Oaxaca: John K Chance, La conquista de la Sierra. Españoles e indígenas de Oaxaca en la época de la Colonia, México, CIESAS/IOC/Fondo Estatal para la Cultura y las Artes, 1998, pp.111-137; Huastecas hidalguense y veracruzana: Antonio Escobar Ohmstede, De la costa a la sierra. Las huastecas, 1750-190o, México, CIESAS/INI, 1998, pp.60-73; Guerrero: Danièle Dehouve, Cuando los banqueros eran santos. Historia económica y social de la provincia de Tlapa, Guerrero, México, Universidad Autónoma de Guerrero, 2001, pp.47-53; Tlaxcala: Franz Tichy, "Pueblos, haciendas y ranchos en el área de Puebla-Tlaxcala”, en Dalhgren Barbro (coord.), Mesoamérica. Homenaje al Dr. Paul Kirchhoff, México, SEP/INAH, 1979; Córdoba: Adriana Naveda, "El censo de 1788, análisis poblacional de ranchos y
} 
Las fuentes muestran la dificultad de definir a cada uno de ellos y el tipo de población, lo que no implicó que no se sepa de manera parcial la calidad y el número de individuos. Por ejemplo, los informes religiosos muestran únicamente a los habitantes "congregados" o "bajo campana" en las misiones, y mencionan a las haciendas como si se conocieran de manera precisa sus límites y composición en ranchos, sin definir la población de ellos y en muy pocos casos la constitución étnica.

Sin embargo, a las localidades se les puede ubicar por dos elementos. El primero era la distancia y dirección que había de un punto a otro; en el caso de la Huasteca potosina era la Villa de Santiago de los Valles la que servía de lugar central y desde la que se calculaba la distancia del sitio dónde se podría encontrar la localidad o escenario mencionado, a pesar que Aquismón fuera el lugar donde administraba y vivía el corregidor desde el primer tercio del siglo XVIII. ${ }^{12}$ El segundo era por la definición del sitio a partir del paisaje o geografía que se agregaba a la distancia para crear la idea de un espacio. Estos elementos, en su conjunto, compartían una visión corográfica, es decir, la representación escrita o pictórica de la experiencia visual de los alrededores, asentamientos y escenarios que están bajo el posesionamiento de un lugar. ${ }^{13}$ Los lugares sin una distinción demográfica, pero sí geográfica, debieron tener un significado para que fueran enunciados, y de los cuales, se tomó algún elemento para la construcción del paisaje de la Huasteca potosina. Cada lugar con individuos podría considerarse parte del territorio y éstos a la vez ayudaron a la construcción de las jurisdicciones de las localidades, más no lo que se conoce como las tierras que pertenecen a los pueblos o haciendas. ${ }^{14}$

haciendas en la Villa de Córdoba”, en C. Blázquez, C. Contreras y S. Pérez Toledo (coords.), Población y estructura urbana; Tacuba, Ángeles Uriega Ponce de León y Antonio Escobar Ohmstede, "La estructura socioeconómica de la jurisdicción de Tacaba en las postrimerías del siglo XVIII. El padrón militar de 1792", en Entorno urbano.Revista de Historia vol.2, n. ${ }^{\circ} 3$, México, Instituto Mora/Universidad Autónoma Metropolitana, 1996, pp.39-82; Morelos: Angélica Guerra, "Población y familia en Santiago de Jiutepec, alcaldía mayor de Cuernavaca, 1715-1793", en América Molina del Villar y David Navarrete (coords.), Problemas demográficos vistos desde la historia. Análisis de fuentes, comportamientos y distribución de la población en México, siglos XVI-XIX, México, El Colegio de Michoacán/CIESAS, 2006, pp.157-198.

12 "Jurisdicción de la Villa de los Valles; año de 1743. Dilixencias Ynformativas, de lo que se compone esta Jurisdicción echas por el Correjidor de ella. Villa de los Valles”, en Archivo General de Indias (AGI), Indiferente, leg.108, f.117.

${ }^{13}$ Barbara E. Mundy, The Mapping of New Spain. Indigenous Cartography and the Maps of the Relaciones Geográficas, Chicago, The University of Chicago Press, 1996, pp. 38-39. Sobre la idea de posesionamiento, Patricia Seed, Ceremonies of Possession in Europe's Conquest of the New World, 1492-1640, Cambridge, Cambridge University Press, 1998.

${ }^{14}$ André Corboz, “El territorio como palimpsesto”, Diógenes n. ${ }^{\circ} 121$, México, 1983, pp.31-32, 
El segundo problema, relacionado con el territorio y la población, es el de las fronteras. Existe poca evidencia para poder delimitar con exactitud la jurisdicción de un pueblo, hacienda, territorio y espacio habitado, así como los límites de la propiedad privada y comunal. ${ }^{15}$ Estos escenarios carecían de una forma geométrica definida y delimitada, aun cuando se plasmaban en el papel pareciese que existían; además se tenía la noción de poder utilizar los recursos a la mano y aprovechar este conocimiento para el beneficio económico. El ejemplo es cómo se encontraban algunas de las misiones de la Huasteca potosina dentro del territorio de las haciendas $\mathrm{y}$ de las cuales se menciona en las fuentes constantes quejas del despojo de las tierras de las misiones. ${ }^{16}$

Un tercer problema es poder definir la calidad étnica y las relaciones sociales de las localidades. Son pocos los estudios, de finales del siglo XVIII, que plantean la distinción de los grupos raciales en el ámbito "micro" y que permiten comprender las relaciones económicas y políticas de las localidades. ${ }^{17} \mathrm{~A}$ este punto se debe agregar los "conflictos" y "convivencia" de los grupos étnicos que ocupaban el espacio de la Huasteca potosina. No se conocen los elementos de etnicidad y cambio sociocultural que permitieron los cambios hacia la producción agrícola; por ejemplo, los

${ }^{15}$ Bernardo García, "Los caminos del ganado y las cercas de las haciendas. Un caso para el estudio del desarrollo de la propiedad rural en México", en Historia y Grafía n. ${ }^{\circ} 5$, México, Universidad Iberoamericana, 1995, pp.22-23; Arij Ouweneel, Ciclos interrumpidos. Ensayos sobre historia rural mexicana. Siglos XVIII-XIX, México, El Colegio Mexiquense, 1998, pp.33-40. Las distintas propuestas en definir las fronteras (ecológica, económica, política) además de un estudio comparativo en Bernd Schröter, "La frontera en Hispanoamérica colonial: un estudio historiográfico comparativo", in Colonial Latin American Historical Review vol.10, n. ${ }^{\circ} 3$, Albuquerque, University of New Mexico, 2001, pp.351-385.

${ }^{16}$ M. Aguilar, "Ganadería”, pp.26-27; "Informes que por mandato de sus prelados superiores hicieron los misioneros de la Custodia de San Salvador de Tampico sobre la fecha de fundación, situación geográfica, número de familias y estado de sus misiones; agregan las causas que consideran han motivado el atraso de sus establecimientos: [Custodia de San Salvador de Tampico] 14 de diciembre de 1761-5 de febrero de 1762", en BN, Fondo Franciscano, 43/ 987.1, f.20v.

${ }^{17}$ Ejemplos de los análisis hechos en la Nueva España y otras regiones de América se encuentran en John E. Kicza, "The Social and Ethnic Historiography of Colonial Latin America: The Last Twenty Years", in William and Mary Quarterly, Tercera Serie, vol.45, n. ${ }^{\circ} 3$, Virginia, Institute of Early American History and Culture, 1988, pp.453-488; David J. Robinson, "Introduction to Themes and Scales", en David J. Robinson (ed.), Social Fabric and Spatial Structure in Colonial Latin America, Syracuse, Syracuse University Press, 1979, pp.12-16; A. Ouweneel, Ciclos interrumpidos, pp.243251; S. Cook y W. Borah, Ensayos sobre historia de la población, t.I, pp.224-288; John K. Chance, Razas y clases de la Oaxaca Colonial, México, INI, 1982, pp.181-227. Para las Huastecas hidalguense y veracruzana sólo se conoce Antonio Escobar Ohmstede, "La estructura socioeconómica de las Huastecas en el siglo XVIII. El censo militar de 1791", en La Palabra y el Hombre. Revista de la Universidad Veracruzana n. ${ }^{\circ}$ 96, Xalapa, Universidad Veracruzana, 1995, pp.5-36. 
pames que adoptaron costumbres de nahuas y huastecos (teenek), o el de los cambios de los grupos por la presencia de las haciendas y ranchos de los españoles. ${ }^{18}$

\subsection{Lugares}

Una localidad la podemos considerar como un sitio o escenario en donde se desarrollan actividades políticas, culturales, sociales, económicas, de subsistencia y de mercado, por parte de una determinada de población y relacionada con los recursos que podían explotar. Cada una de estas unidades era parte del territorio, como proyecto y producto de todo tipo de relaciones de los escenarios, y que al final se organizaba para construir el paisaje cultural. ${ }^{19}$ Esta configuración se ha estudiado a partir de la localización de asentamientos o unidades políticas de un sistema implantado por los españoles en el siglo Xvi y que evolucionó en el control administrativo de las localidades y su jurisdicción. ${ }^{20}$

Dentro del sistema colonial no existía un control territorial absoluto ni por parte de los alcaldes mayores, los tenientes de justicia, los curas y frailes, y en muchos casos ni por los gobiernos indígenas. En gran parte de la Nueva España, sobre todo en el Altiplano central, el sur y sureste indígena se pueden observar tres formas de movilidad poblacional de los indios en el siglo XvIII. La primera, la huida, se caracterizó por escapar del sistema administrativo español (civil y eclesiástico), haciendas y estancias hacia territorios no conquistados y evangelizados o poco conocidos por los no indios, como pudieron ser los montes y bosques, la "montaña" yucateca o territorios hasta cierto punto lejanos. ${ }^{21}$ La segunda, la "deriva", como lo define Nancy Farris para Yucatán, era el traslado de una población a otra, lo que se puede conocer como migración, en la que un grupo de individuos buscaba el sustento sin regresar a su comunidad de origen (cuadrillas); en otros algunos indivi-

\footnotetext{
18 Pedro Carrasco, "La transformación de la cultura indígena durante la colonia", en Historia Mexicana vol.xxv, n. ${ }^{\circ}$ 2, México, El Colegio de México, 1975, pp.175-203; Erwin P. Grieshaber, "Hacienda-Indian Community Relations and Indian Acculturation: An Historiographical Essay", in Latin American Research Review vol.XIV, n. ${ }^{\circ}$ 3, Durham, University Duke Press, 1979, pp.107-128.

19 A. Corboz, "El territorio", pp.21, 31-32.

${ }^{20}$ Por ejemplo Peter Gerhard, Geografía histórica de la Nueva España, 1519-1821, México, UNAM, 1986, pp.363-367, analiza los sitios de la jurisdicción de la Villa de los Valles y el resto de las jurisdicciones políticas y religiosas de la Nueva España como asentamientos de población y deja "en el aire" la idea de concentración en unidades establecidas, por ejemplo, los pueblos.

${ }^{21}$ Pedro Bracamonte y Sosa, La conquista inconclusa de Yucatán: los mayas de la montaña, 15601680, México, CIESAS/UQROO/Miguel Ángel Porrúa, 2001.
} 
duos buscaban formar familias o encontrar trabajo en localidades distintas a las de origen; y la tercera, la dispersión, en donde los indios disolvieron los vínculos sociales y buscaron nuevos sitios dónde ubicarse o sencillamente se asentaban en aquellos territorios que les permitía sembrar de manera itinerante. ${ }^{22}$ Resaltando el caso que aquí nos interesa, podemos considerar que las diferencias étnicas, culturales y ecológicas de los grupos (pames, huastecos, nahuas, otomíes, mecos) diferenciaban la apropiación del espacio, y que con la política de congregación española se intentó modificar los patrones de los grupos, en especial los de cazadoresrecolectores.

En la jurisdicción de Villa de los Valles, los diversos funcionarios civiles y eclesiásticos informaban de las huidas por el cobro de tributos y los efectos de las epidemias y hambrunas, dando la impresión de un despoblamiento de las jurisdicciones. Hay dos ejemplos que sobresalen. El primero es el de Tamuín que fue abandonada por sus habitantes indios al ser matriculados en los años de 1770 y 1776 , a pesar de contar con el privilegio de ser fronterizos. Y estar exentos del pago. ${ }^{23} \mathrm{El}$ segundo se refiere a Tancanhuitz, en el cual debido a los abusos del párroco en el servicio personal, ocasionaba "extrañamiento" en el pueblo e inconformidad entre los indios. ${ }^{24}$ Los fenómenos naturales adversos, así como las enfermedades tenían, en varios casos, relación directa con la huida de los indios de los pueblos eran las pestes, plagas, heladas y hambrunas provocadas por sequías o huracanes.

\footnotetext{
${ }^{22}$ N. Farris, La sociedad maya, pp.318-348. Para conocer las fuentes que se pueden utilizar para estudiar la movilidad de la población indígena en el siglo XVI, Juan Manuel Pérez, "Fuentes para la historia de la movilidad de la población indígena en Nueva España", en América Latina en la Historia Económica. Boletín de fuentes. Economía indígena n. ${ }^{\circ} 12$, México, Instituto Mora, 1999, pp.2737. En el caso de Oaxaca las movilidad de la población estaba condicionada por el medio ambiente (falta de agua y tierra, epidemias) y las relaciones interétnicas de los grupos. J. Chance, La conquista de la Sierra, p.111.

23 "Relación del estado actual de las misiones de Tampico. 1778", en Carlos González Salas, La Evangelización en Tamaulipas. Las misiones novohispanas en la costa del Seno Mexicano (15301831), México, Instituto de Investigaciones Históricas/UAT, 1998, p.413.

${ }^{24}$ Archivo General de la Nación (AGN), Historia, vol.72 (2), ff.350-351; Peter B. Mandeville, La jurisdicción de la Villa de Santiago de los Valles en 170o-180o, San Luis Potosí, México, Academia de Historia Potosina, 1976, pp.107-108.
} 


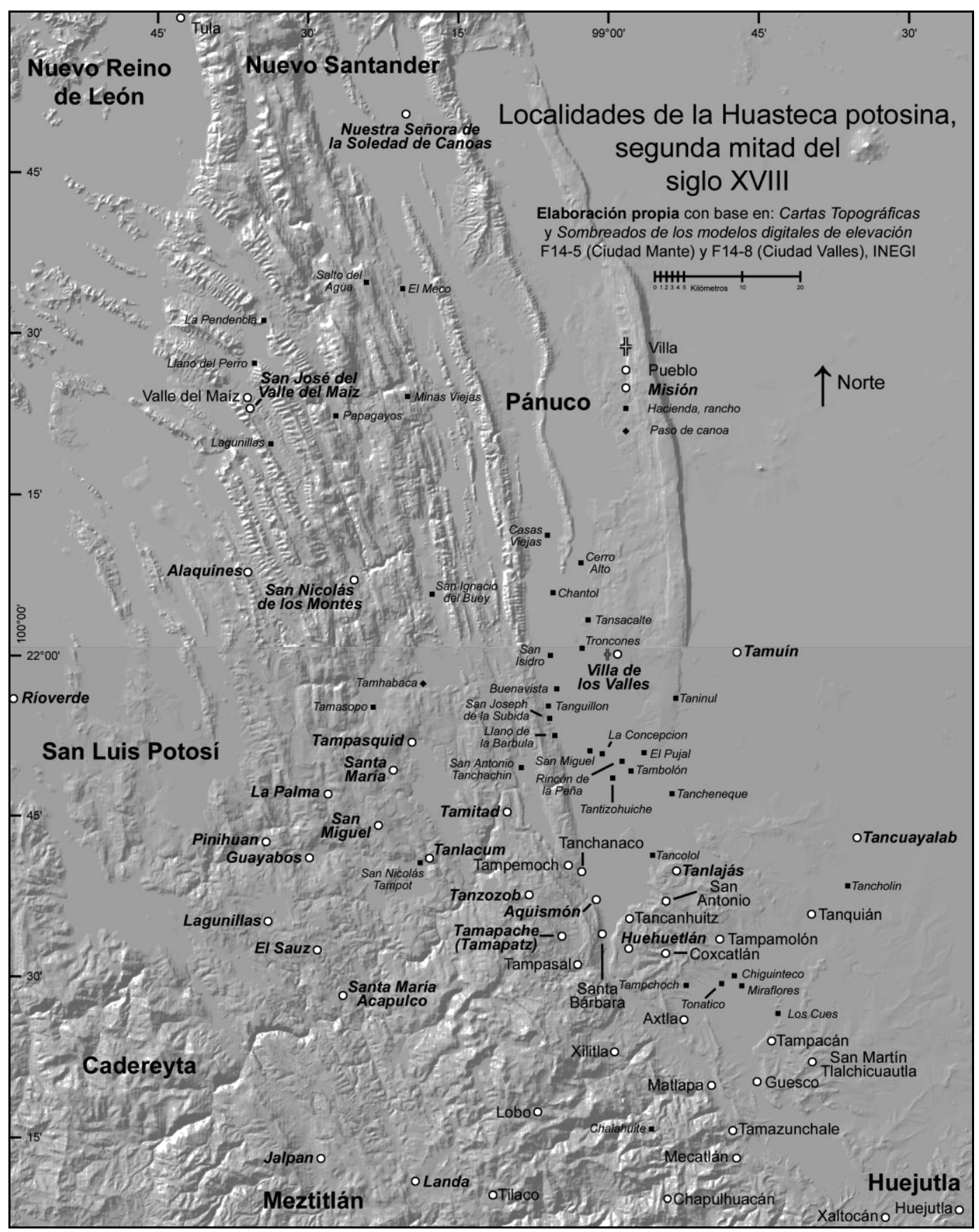

En el caso de la "deriva" en las Huastecas poco se sabe, así de cómo fue la migración entre los pueblos, aunque con la información proveniente de las noticias estadísticas de 1826 sabemos de la existencia de cuadrillas, y sobre todo debemos 
considerar a los indios "laboríos", quienes eran perfectamente diferenciados de los peones, arrendatarios y medieros, aunque a éstos no se les diferenciaba por su calidad étnica, suponemos que se trataban de mulatos, mestizos e indígenas. La fundación de nuevos sitios da una pista de cómo se constituyeron algunas localidades en pueblos. También en este período se acentuó el fenómeno de separación de los pueblos sujetos de sus cabeceras y la formación de nuevos tipos de localidad conocidas como ranchos, que a lo largo del tiempo se constituyeron en pueblos. ${ }^{25}$ Valgan dos ejemplos. El caso de Santa Ana Tanlajas que fue fundado en un potrero de la Hacienda de Santa Ana Tancolol. ${ }^{26}$ Los manuscritos sugieren de forma constante esta historia, pero parece que la misión fue fundada en 1624 y después abandonada en varias ocasiones hasta que en 1733 en el paraje nombrado Tanlatax, donde se encontraba la antigua misión de Tancuayalab se le otorgaron las 600 varas de fundo legal, aun cuando a las misiones no se les otorgaban los títulos primordiales. ${ }^{27}$ Otra fundación tardía, en 1765, es la separación de los barrios que componían San Juan Tansuio y que se solicitaron la separación de su cabecera para vivir en "policía” por contar con 116 familias de tributarios enteros y maestro de escuela. ${ }^{28} \mathrm{El}$

25 Bernardo García Martínez, "Pueblos de Indios, Pueblos de Castas: New Settlements and Traditional Corporate Organization in Eighteenth-Century New Spain”, en Arij Oweneel y Simon Miller (eds.), The Indian Community of Colonial Mexico. Fifteen Essays on Land Tenure, Corporate Organizations, Ideology and Village Politics, Amsterdam, CEDLA, 1990, pp.107-108.

26 “Relación del estado actual de las misiones de Tampico. 1778”, en C. González, La Evangelización en Tamaulipas, p.412. Para Joaquín Meade, Historia de Valles. Monografía de la Huasteca potosina, México, Sociedad Potosina de Estudios Históricos, San Luis Potosí, 1970, p.79, Villa de los Valles era la única que tenía fundo legal de 600 varas, una legua de ejidos, y 1250 varas más.

27 "Informes que por mandato de sus prelados superiores hicieron los misioneros de la Custodia de San Salvador de Tampico sobre la fecha de fundación, situación geográfica, número de familias y estado de sus misiones; agregan las causas que consideran han motivado el atraso de sus establecimientos: [Custodia de San Salvador de Tampico] 14 de diciembre de 1761-5 de febrero de 1762", en BN, Fondo Franciscano, 43/ 987.1, ff. 4v-5; "El virrey aprueba y confirma las diligencias ejecutadas por la justicia de la Villa de Valles sobre la reedificación del pueblo de Tanlajás y manda se le enteren a sus naturales las seiscientas varas en la forma que contiene. Villa de Valles", en AGN, Indios, exp.9, ff.14, 19-19v.

28 "El virrey concede licencia al alcalde y demás naturales de varias congregaciones y barrios, que se hallan con el título de San Juan Tansullo, sujeto a la doctrina del partido de Tampamolon, jurisdicción de la Villa de Valles; para que se reduzcan a pueblo y quedan en su consecuencia, elegir anualmente para su gobierno los alcaldes, regidores y demás oficiales de república, que correspondan al número de indios que se congreguen y quede establecido dicho pueblo formalmente con la iglesia y lo demás correspondiente al culto divino", en AGN, Indios, vol.61, exp.68, ff.51v-52. 
Sauz, en 1761-1762, estuvo fundado en un potrero de apenas una fanega de sembradura. ${ }^{29}$

Un aspecto que nos permite entender la "deriva" fueron los conflictos y las quejas constantes que se registraron en contra de las haciendas y la escasez de tierras de labranza. Los pueblos y misiones fueron los más afectados por dos causas. La primera relacionada con la ecología (naturaleza), ya que se consideraba que la tierra era "árida y pedregosa" por lo que no se lograban buenas cosechas; y la segunda, que los indios que buscaban el sustento en las haciendas "le covren amor a las Haciendas y se lo pierdan a sus pueblos". ${ }^{30}$ Por lo menos los pobladores de La Palma (pames), Santa María Acapulco (pames), Guayabos (pames), Tanlacum (pames) y San Diego (pames) no tenían tierras por causa de la Hacienda de San Nicolás Tampot; y los de Tamasquid (huastecos), Santa María (pames), San Miguel (pames), y Tanlacum (pames) por la Hacienda de Amoladeras. Otros sitios como Huehuetlán (huastecos y nahuas), Santa Ana Tanlajás (huastecos) y Tamuín (huastecos) arrendaban tierras para su sustento. ${ }^{31}$

Por último, la población dispersa, se encontraba en la parte sur y oeste de la circunvalación de la jurisdicción de la Villa de los Valles. Estas localidades eran Tamapache (nahuas y pames), Tanzozob (nahuas y pames), Tamitas (huastecos), Tampasquid (huastecos), San Miguel (pames), Santa María Tampaxilin (pames), Tamasopo (pames), Tanlacum (pames), San Diego, El Sauz (pames), Santa María Acapulco (pames), San Marcos (pames), Guayabos (pames), Xilitla (nahuas, otomíes, pames y mecos) y Tamazunchale (nahuas). Pareciera que la jurisdicción de Villa de los Valles era un círculo con características centrípetas en donde la distancia hacia el centro (lugar central) representa un mayor grado en la representatividad de la población en localidades.

29 "Informes que por mandato de sus prelados superiores hicieron los misioneros de la Custodia de San Salvador de Tampico sobre la fecha de fundación, situación geográfica, número de familias y estado de sus misiones; agregan las causas que consideran han motivado el atraso de sus establecimientos: [Custodia de San Salvador de Tampico] 14 de diciembre de 1761-5 de febrero de 1762", en BN, Fondo Franciscano, 43/ 987.1, f.20v. La fanega de sembradura oscila entre las 3.566 y 7.500 hectáreas que corresponden a Huazalingo y Huejutla, A. Escobar Ohmstede, De la costa, p.101.

30 "Relación del estado actual de las misiones de Tampico. 1778”, en C. González, La Evangelización de Tamaulipas, p.426.

31 "Jurisdicción de la Villa de los Valles; año de 1743. Dilixencias Ynformativas, de lo que se compone esta Jurisdicción echas por el Correjidor de ella. Villa de los Valles”, en AGI, Indiferente, leg.108, f.115v; "Informes que por mandato de sus prelados superiores hicieron los misioneros de la Custodia de San Salvador de Tampico sobre la fecha de fundación, situación geográfica, número de familias y estado de sus misiones; agregan las causas que consideran han motivado el atraso de sus establecimientos: [Custodia de San Salvador de Tampico] 14 de diciembre de 1761-5 de febrero de 1762", en BN, Fondo Franciscano, 43/ 987.1, ff.5-5v, 7v-8v, 20v-21v. 
La ubicación de localidades en la Sierra Madre de grupos nahuas y huastecos, sedentarios y de forma de subsistencia mixta (agricultura, caza y recolección) son parecidos a los del centro de la Nueva España, aun cuando se encontraban en frontera en 1743, y mucho tiempo después de consolidarse la Colonia del Nuevo Santander en 1778. Los sitios donde habitaban estos grupos tenían la característica de ser congregados. En cambio los chichimecos, pames y otomíes tenían la característica de ser dispersos, cazadores-recolectores, aun cuando muchos de los considerados como grupos sedentarios tenían patrones de asentamientos dispersos y muy poco concentrados en localidades "urbanas" (pueblos). ¿Por qué es necesario mencionar las características básicas de estos grupos? La respuesta está en lo acaecido en 1743, donde un grupo de indios huastecos se hacían pasar por pames. Esta localidad, que parecía una ranchería, se encontraba cerca de Aquismón. ${ }^{32}$ Un caso similar se registró en 1761-1762, pero en esta ocasión unos pames "habiendo soltado las greñas y mantillas que vestian, han aprendido el idioma huasteco" en una ranchería de Aquismón (Santa Bárbara Tampasal). ${ }^{33}$ A pesar de la confusión es seguro que fuera el mismo sitio en donde los indios cambiaban de grupo étnico Esto puede significar que la resistencia de los huastecos era confundir para no pagar obvenciones y tributos.

Sin embargo, es posible que los pames optaran por cambiar su "entidad sociocultural" (¿otro tipo de mestizaje?) como una forma de resistencia o como una posibilidad de acceder a tierras que no podrían obtener al seguir siendo considerados "indios de campana". ${ }^{34}$ Un aspecto que no habría que descartar, es el hecho que pudo ser una manera de ocultarse por lo sucedido unos años antes cuando se intentó congregarlos a lo largo de la colonia en Valle del Maíz y el Valle de Lágrimas (que luego se convertirá en San José del Valle del Maíz). ${ }^{35}$ Todos los esfuerzos fueron inútiles porque los informes de los misioneros constantemente tienen la queja de no poder congregar a los indios. Por esta situación fueron tomados por "bárbaros"

\footnotetext{
32 "Jurisdicción de la Villa de los Valles; año de 1743. Dilixencias Ynformativas, de lo que se compone esta Jurisdicción echas por el Correjidor de ella. Villa de los Valles”, en AGI, Indiferente, leg. 108, f. 117 .

33 "Informes que por mandato de sus prelados superiores hicieron los misioneros de la Custodia de San Salvador de Tampico sobre la fecha de fundación, situación geográfica, número de familias y estado de sus misiones; agregan las causas que consideran han motivado el atraso de sus establecimientos: [Custodia de San Salvador de Tampico] 14 de diciembre de 1761-5 de febrero de 1762", en BN, Fondo Franciscano, 43/ 987.1, ff.10-10v.

${ }^{34}$ Cynthia Radding, Wandering Peoples. Colonialism, Ethnic Spaces, and Ecological Frontiers in Northwestern México, 1700-1850, Durham y Londres, Duke University Press, 1997.

${ }^{35}$ Rafael Montejano y Aguiñaga, El Valle del Maíz, S.L.P., San Luis Potosí, México, UASLP, 2002, pp.10-113.
} 
y se les llevó en colleras y como esclavos a fundar la Colonia del Nuevo Santander. Este hecho fue constante. Los españoles y mulatos al servicio de José de Escandón visitaban las localidades pames para tomarlos como trabajadores de las haciendas en la que se les quitaban todas sus prendas y al no soportar los maltratos preferían huir y vivir dispersos. ${ }^{36}$

Los tipos de movilidad estuvieron presentes a lo largo de la segunda mitad del siglo XVIII. Para comparar la calidad de los grupos era necesario que en los informes, civiles y religiosos, contaran con información cualitativa de los indios y su situación en el espacio (congregado, disperso). Dos manuscritos permiten esto. El primero, de 1743, firmado por el corregidor y teniente de capitán general Francisco de Lazcano, aporta la cantidad de familias, la lengua que hablaban y su situación. El de 1778 de fray Manuel Francisco Galindo también contiene la misma información que el anterior, además que agrega la cantidad de almas. ${ }^{37}$ En 1743 había en total $57 \%$ de indios asentados en pueblos contra un $43 \%$ bajo la jurisdicción de algún sitio o identificados con él por los informes de los españoles. Para 1778 los indios asentados fueron el $81 \%$ y los dispersos $19 \%$. A primera vista parece que los indios se congregaron y se establecieron en los pueblos. Sin embargo, si agregamos la cifra de la población que no conocemos su calidad étnica para ese año, que se encontraba en haciendas y ranchos, el porcentaje se eleva al total de $42 \%$ de indios dispersos. Apenas se logró reducir o congregar el 15\% de la población indígena. Si se analiza el caso de los indios pames y las localidades en que se encuentran pames y huastecos en conjunto se tienen porcentajes de $25 \%$ y $30 \%$ asentados en pueblos, y 70 \% y $64 \%$ de indios dispersos y localizados en la jurisdicción de algún pueblo en 1743. Este patrón cambia en 1778 cuando se encuentran $36 \%$ de pames en asentamientos y $64 \%$ dispersos.

Los porcentajes del patrón de asentamiento de los indios sugieren que a pesar de la fundación de la Colonia del Nuevo Santander en 1748, la población continuó con formas de localización similares y que los cambios no estuvieron relacionados con los asentamientos o por lo menos es lo que se puede apreciar a primera vista. A esto se debe agregar el análisis de la población en los dos niveles

\footnotetext{
36 "Informes que por mandato de sus prelados superiores hicieron los misioneros de la Custodia de San Salvador de Tampico sobre la fecha de fundación, situación geográfica, número de familias y estado de sus misiones; agregan las causas que consideran han motivado el atraso de sus establecimientos: [Custodia de San Salvador de Tampico] 14 de diciembre de 1761-5 de febrero de 1762", en BN, Fondo Franciscano, 43/ 987.1, ff.8v.-9,17v,19.

37 "Jurisdicción de la Villa de los Valles; año de 1743. Dilixencias Ynformativas, de lo que se compone esta Jurisdicción echas por el Correjidor de ella. Villa de los Valles", en AGI, Indiferente, leg.108, ff.109v-120v.; "Relación del estado actual de las misiones de Tampico. 1778", en C. González, La Evangelización de Tamaulipas, pp.403-429.
} 
que con anterioridad se sugirieron, lo que refleja la variedad de grupos étnicos que se encontraban ubicados en distintas localidades. En la zona sureste, la más cercana a la actual Huasteca hidalguense, la población era nahua. Al suroeste se encontraban los nahuas, otomíes, pames y mecos. Lo que hacía la distinción entre un esespacio y otro era la Sierra Madre. Al noroeste se encontraban los pames, y al norte lo huastecos. Como no existían fronteras establecidas entre cada una de las zonas en donde se ubican mejor localidades con distintas calidades étnicas en muchos casos se daba el contacto de una manera intensa, no solamente en términos culturales, sino también biológicos y económicos.

La población no india tenía un patrón de asentamiento en localidades no definidas como haciendas y ranchos, por lo menos en 1743. En la década de los setenta del siglo XVIII en las fuentes aparece una distinción más clara de dónde se encontraban. El 68\% se localizaba en pueblos, mientras que el $31 \%$ en haciendas y ranchos. También se puede conocer el patrón de asentamiento de cada una de las castas (tabla 1).

Se entiende que los pueblos de indios eran localidades con recursos y con un tipo de organización política-administrativa para enfrentar las demandas internas y externas de cualquier situación; además de contar con una jurisdicción y administración política-administrativa. ${ }^{38}$ En la Huasteca potosina estas localidades tenían una forma indistinta y no es posible definir los límites de cada uno en términos de fronteras, como lo comentamos al principio de este artículo, pero es posible identificar cómo controlaban otros sitios y escenarios a partir de la jurisdicción territorial. Esto en algunos casos se puede entender como la relación cabecera-pueblo sujeto, o de otras formas, como pueblo-barrios o tlaxicales, pueblo-hacienda, pueblos-estancias, pueblos-misión y pueblo-paso de canoa. Cada uno de los casos tiene distinta complejidad para analizarlos.

\footnotetext{
${ }^{38}$ B. García, "Pueblos de Indios", p. 105; Dorothy Tanck de Estrada, Pueblos de indios y educación en el México colonial, 1750-1821, México, ColmEx, 1999, p.33; Antonio Escobar Ohmstede, "Los pueblos indios de las Huastecas a través de cien años de historia", en Manuel Ferrer Muñoz (coord.), Los pueblos indios y el parteaguas de la Independencia de México, México, Instituto de Investigaciones Jurídicas/UNAM, 1999, pp.105-165; Stephanie Wood, "The Fundo Legal or Lands Por Razón de Pueblo: New Evidence from Central New Spain”, in A. Oweneel y S. Miller (eds.), The Indian Community, pp.117-129.
} 
Tabla 1: Patrón de asentamiento de la población no indígena de la Huasteca potosina, siglo XVII

\begin{tabular}{|c|c|c|c|c|c|c|c|}
\hline Años & Castas & $\begin{array}{l}\text { Población } \\
\text { en pueblos }\end{array}$ & $\%$ & $\begin{array}{l}\text { Haciendas } \\
\text { y ranchos }\end{array}$ & $\%$ & Total & $\begin{array}{c}\% \\
\text { Total } \\
\end{array}$ \\
\hline \multirow{4}{*}{1743} & Españoles & - & - & \multirow{3}{*}{2.384} & \multirow{3}{*}{100} & \multirow{3}{*}{2.384} & \multirow{3}{*}{100} \\
\hline & Mulatos & - & - & & & & \\
\hline & Indefinidos & - & - & & & & \\
\hline & Total & - & - & 2.384 & 100 & 2.384 & 100 \\
\hline & & & & & & & \\
\hline \multirow{4}{*}{1778} & Españoles & 716 & 23 & 27 & 1 & 743 & 24 \\
\hline & Mulatos & 1.353 & 45 & 214 & 7 & 1.567 & 52 \\
\hline & Indefinidos & - & - & 685 & 23 & 685 & 23 \\
\hline & Total & 2.069 & 68 & 926 & 31 & 2.995 & 99 \\
\hline
\end{tabular}

Fuentes: "Jurisdicción de la Villa de los Valles; año de 1743. Dilixenzias Ynformativas, de lo que se compone esta Jurisdicción echas por el Correjidor de ella", en AGI, Indiferente, leg.108; "Relación del estado actual de las misiones de Tampico. 1778”, en C. González, La Evangelización en Tamaulipas, pp.403-429.

Las descripciones en la mayoría de los casos son similares en torno a los elementos geográficos en los que se asentaron las localidades, y en dos casos, Tanlajás y El Sauz fueron fundados en potreros de haciendas. ${ }^{39}$ En segundo lugar se debe saber cuántos pueblos, como asentamientos, había en la jurisdicción de la Villa de los Valles. En 1743 se cuantificaron 39 y en 1770 se mencionaron 46. Para 1790 la cifra cambia a 30 pueblos y a los cuatro años se encuentran $23 .{ }^{40}$ La varia-

39 "Informes que por mandato de sus prelados superiores hicieron los misioneros de la Custodia de San Salvador de Tampico sobre la fecha de fundación, situación geográfica, número de familias y estado de sus misiones; agregan las causas que consideran han motivado el atraso de sus establecimientos: [Custodia de San Salvador de Tampico] 14 de diciembre de 1761-5 de febrero de 1762", en BN, Fondo Franciscano, 43/ 987.1, ff.5, 19v.; "Relación del estado actual de las misiones de Tampico. 1778”, en C. González, La Evangelización de Tamaulipas, p.412.

40 "Jurisdicción de la Villa de los Valles; año de 1743. Dilixencias Ynformativas, de lo que se compone esta Jurisdicción echas por el Correjidor de ella. Villa de los Valles”, AGI, Indiferente, leg.108, ff.109v-119; "Yndize comprehensibo de todos los Goviernos, corregimientos y Alcaldias mayores que contiene la Governacion del Virreynato de Mexico. Sus anexas Audiencias y Frutos que produce cada Pais en que pueden diverttir sus quinquenios los Provistos, que no tienen practica, dispuesto por el A.B.C. para la maior intelijencia. Año de 1770", en NYPL, Phillips, Ms. 15796, ff.35v-36; Hugo Castro Aranda, Censo de población de la Nueva España. 179o, México, Secretaría de Programación y Presupuesto/Dirección General de Estadística, 1977, pp.71-102; "Instrucción de la guía política, militar, y eclesiástica, que don José Luis Plasencia y Ugarte subdelegado de esta jurisdicción de Villa de Valles, ministró al señor intendente de San Luis Potosí, el día 20 de febrero de 1794", en AHESLP, Intendencia, leg. 1792-1795, e Intendencia, leg. 1770-1779, exp.9; P. Gerhard, Geografía histórica, p.367; J. Meade, Historia de Valles, p.93. 
ción en las cifras no es posible entenderla sin pensar que las jurisdicciones sufrieron cambios, como separaciones, congregaciones o subregistro. Así tenemos que Xilitla y Xaltocan fueron transferidas a otras unidades políticas durante la segunda mitad del siglo XVIII. El primero regresó a Villa de los Valles en un momento que no ha sido determinado, y el segundo se quedó en la Huasteca hidalguense cuyo centro político-administrativo se encontraba en Huejutla. También Soledad de Canoas o Tambuanchin se anexó a la Colonia del Nuevo Santander cuando José de Escandón fundó las misiones, villas y pueblos circa 1748-1750 y se perdió la parte norte, de frontera, de Valles..$^{41}$ La complejidad de estudiar los pueblos de indios es la relación de subordinación entre ellos y la transformación de cada uno. Por lo menos a mediados del siglo XVIII se encontraban 9 unidades políticas de cabeceras-pueblos sujetos que se fragmentaron por el aumento de población y por las dificultades de comunicación con la cabecera. ${ }^{42}$

Si existe problema en definir los términos del funcionamiento o conformación de los pueblos, con las haciendas sucede lo mismo. La localización de las haciendas como localidades es difícil y compleja. La ubicación se hacía a partir de los pueblos, y si estos se localizaban a partir de un elemento geográfico, la referencia se hacía hacia un punto cardinal u otra localidad. Las haciendas de la Huasteca potosina han sido definidas como en otros sitios de la Nueva España, a partir de la propiedad e infiriendo un lugar fijo como centro, y sólo se conoce su evolución en términos de propiedad. ${ }^{43}$ Pero el estudio de su localización, territorio y la relevancia del control de otros sitios, ya sea subordinado, y como punto de control de otros sitios ha quedado olvidada.44 Por ahora las definiciones de producción y tenencia de la tierra de los estudios que dejan a las haciendas sin el contexto dónde se ubican, su escenario, y su relación con otras localidades para entender el territorio,

\footnotetext{
${ }^{41}$ Fray Joseph Joachin García, Informe privado contra Escandón, México, Imprenta "Beatriz de Silva”, 1946, p.12; P. Gerhard, Geografía histórica, p.365; del mismo autor La frontera norte de la Nueva España, México, UNAM, 1996, p.451.

42 D. Dehouve, Cuando los banqueros eran santos, pp.168-175; B. García, "Pueblos de Indios, Pueblos de Castas", pp.107-108.

43 Miguel Aguilar Robledo, "Haciendas y condueñazgos en la Huasteca potosina: notas introductorias", en J. Ruvalcaba (coord.), Nuevos aportes al conocimiento, pp. 126-135; Antonio Escobar Ohmstede y José Alfredo Rangel Silva (coords.), Haciendas, negocios y política en San Luis Potosí, siglos XVIII al XX, México, El Colegio de San Luis, 2011.

${ }^{44}$ Bernardo García, "Los poblados de hacienda: personajes olvidados en la historia del México rural”, en Alicia Hernández Chávez y Manuel Miño Grijalva (coords.), Cincuenta años de Historia en México. En el Cincuentenario del Centro de Estudios Históricos vol. I, México, Colmex, 2001, p.332.
} 
están fuera. ${ }^{45}$ Entonces las haciendas en el siglo XVIII eran territorios independientes de otras localidades pero que dependían de ellas para ubicarlas en el contexto y de las cuales se tenían infinidad de quejas por la extensión de sus terrenos.

De los años de 1743-1778 no se tenía una idea clara de la cantidad de localidades como ranchos o haciendas. Existía una clara intención de "meter" dentro de la jurisdicción de una localidad otros sitios, en este caso, escenarios que tenían una propiedad sin una delimitación establecida y sin un conocimiento exacto de su ubicación. Para 1790-1819 la situación de las haciendas, ranchos (dependientes e independientes) y estancias es más clara. En 1790 las localidades que registran mayor número de sitios como haciendas fueron Tamazunchale, Tamuín y Valle del Maíz. En cambio se registra mayor cantidad de ranchos independientes en la Villa de los Valles, Valle del Maíz y Aquismón.

La gran diferencia del informe de 1794 es que se agregaron los nombres de los sitios, y en pocos casos el nombre del propietario. Las localidades de haciendas eran Valles, Tamazunchale, Valle del Maíz y Tampamolón. Las que tenían mayor cantidad de ranchos se encontraba en las mismas jurisdicciones. Con el cambio de siglo también hubo cambios. Villa de los Valles, Tamazunchale y Tampamolón son las que registran mayor cantidad de haciendas. Y la cantidad de ranchos independientes en Valles, Tancuayalab, Valle del Maíz, Tanlajás y Tampamolón es mucho mayor a la de 1790. La hipótesis que explique estos cambios fue el fraccionamiento de tierras. El ejemplo más claro es el de las tierras de Felipe Barragán, dueño de grandes extensiones de tierras en la Huasteca potosina. En otros casos se crearon haciendas y ranchos por la usurpación de tierras a las localidades indígenas que fueron convertidas en propiedad de particulares. ${ }^{46} \mathrm{Si}$ se sigue la evolución de la enumeración de propiedades a lo largo del siglo XviII es evidente que no existe una definición a priori de lo que podría ser una hacienda, rancho o estancia; por la aparición y desaparición de nombres queda claro la multiplicación de lugares y porque las grandes extensiones territoriales se fraccionaron en unidades más pequeñas y en algunos casos algunos potreros, como mencionamos más arriba, se constituyeron en pueblos. ${ }^{47}$

\footnotetext{
45 Véanse los estudios de haciendas en Magnus Mörner, "The Spanish American Hacienda: A Survey of Recent Research and Debate", in Hispanic American Historical Review vol.53, n. ${ }^{\circ}$, Durham, Duke University Press, 1973, pp.185-186, 194-199; Eric Van Young, "La historia rural de México desde Chevalier: historiografía de la hacienda colonial", en Historias n. ${ }^{\circ} 12$, México, INAH, 1986, pp.23-41.

${ }^{46}$ M. Aguilar, “Haciendas y condueñazgos”, pp. 126-134; José Alfredo Rangel, Capitanes a guerra, linajes de frontera. Ascenso y consolidación de las élites, en el oriente de San Luis, 1617-1823, México, COLMEX, 2008.

${ }^{47}$ B. García, "Los poblados de hacienda”, p.334.
} 
Es bueno notar que los sitios como ranchos, también, podían ser lugares sin ubicación fija. Esto quiere decir que su localización variaba a partir de la temporalidad y de la producción a la que estaba orientada. La movilidad de estos sitios apenas y es mencionado en la Huasteca potosina y poco se conoce. Esta idea sugiere que los ranchos eran lo que tenían mayor movilidad en la jurisdicción de la Villa de los Valles. ${ }^{48}$ Siguiendo este punto, lo mismo sucedería con las cuadrillas de indios que trabajan en los territorios de las haciendas, con gran movilidad espacial y sujetos a la jurisdicción de la localidad.

Es claro que las localidades y su jurisdicción no tenía fronteras definidas y claras. La ampliación del territorio de los lugares, en varios casos, iba de la mano de lo económico. Esto servía como una estrategia de quienes pudieran tener la facilidad de "mover" gran cantidad de productos (incluimos el ganado) aprovechando la escasa definición de perímetros. Sin embargo, como se verá en el estudio de la economía india y no india, cada uno de los grupos utilizó diversas y distintas estrategias para lograr el beneficio de sus intereses y permitirnos entender la circulación de mercancías.

\section{Los habitantes en la Huasteca potosina}

En general, poco es lo que se conoce en torno al tipo, calidad y cantidad de población en las Huastecas en el siglo XVIII y principios del siglo XIX. Los estudios que tratan la diferencia entre indios y no indios para comprender la organización política y social de los pueblos indios de la Huasteca veracruzana e hidalguense son po$\cos { }^{49}$ por otro lado, para las mismas jurisdicciones, existe el análisis demográfico de los pueblos y la estructura socioeconómica de ellas, mostrando las diferencias ocupacionales y sugiriendo la distribución de población en pueblos, haciendas y ranchos, haciendo la distinción étnica en los mismos. ${ }^{50}$

\footnotetext{
${ }^{48}$ M. Aguilar, "Ganadería”, p.14, nota 17. B. García, "Los caminos de ganado", pp.13-29, resalta la importancia de la trashumancia, en términos de localización y paisaje, y que para las Huastecas no han sido estudiados.

49 A. Escobar Ohmstede, "Los pueblos indios"; del mismo autor "El comercio en las Huastecas. Los indígenas y su participación, siglo XVIII", en Jorge Silva Riquer y Antonio Escobar Ohmstede (coords.), Mercados indígenas en México, Chile y Argentina. Siglos XVIII-XIX, México, Instituto Mora/CIESAS, 2000, pp.93-95; María Luisa Herrera Casasús, Presencia y esclavitud del negro en la Huasteca, México, IIH/UAT/Miguel Ángel Porrúa, 1989, pp.29-62; véase también la nota 21 de la introducción de A. Escobar Ohmstede y L. Carregha (coords.), El siglo XIX.

50 A. Escobar Ohmstede, "La estructura socioeconómica”, pp.5-36; David Brading, "Grupos étnicos; clases y estructura ocupacional en Guanajuato (1792)”, en Historia Mexicana vol.xxI, n. ${ }^{\circ} 3$, México,
} 
Para elaborar este apartado se tomaron las cifras que se obtuvieron de informes civiles y religiosos. La separación de los datos se estableció a partir del criterio de elaboración de cada uno de ellos (civil y religioso). Lo anterior se hizo para evitar que en la muestra se supusieran grandes crecimientos o decrecimientos que están relacionados con el tipo de población de la localidad mencionada, en unos las misiones, y otras de la población total.

Tabla 2: Población de la Huasteca potosina a partir de informes civiles, 1743-1826

\begin{tabular}{|c|c|c|c|c|c|}
\hline Años & Indios & $\%$ & No indios & $\%$ & Fuentes \\
\hline 1743 & 45.032 & 95 & 2.384 & 5 & AGI, Indiferente, leg.108, ff.109v-120v. \\
\hline 1765 & 20.664 & 99 & $234^{*}$ & 1 & AGI, Audiencia de México, leg.2104. \\
\hline 1771 & 25.164 & 97 & $854^{*}$ & 3 & AGI, Audiencia de México, leg.2104. \\
\hline 1777 & 25.686 & 94 & $1.682^{*}$ & 6 & AGI, Audiencia de México, leg.2104. \\
\hline 1783 & 24.126 & 92 & $2.142^{*}$ & 8 & AGI, Audiencia de México, leg.2104 \\
\hline 1790 & 23.456 & 79 & 6.370 & 21 & H. Castro, Censo de población, pp.71-102. \\
\hline 1794 & 26.849 & 74 & 9.589 & 26 & $\begin{array}{l}\text { "Instrucción de la guía política, militar, y ecle- } \\
\text { siástica, que don José Luis Plasencia y Ugarte } \\
\text { subdelegado de esta jurisdicción de Villa de } \\
\text { Valles, ministró al señor intendente de San } \\
\text { Luis Potosí, el día } 20 \text { de febrero de } 1794 \text { años", } \\
\text { en AHESLP, Intendencia, } 1792-1795 \text {, exp.15 e } \\
\text { Intendencia, 1770-1779, exp. ; J. Meade, His- } \\
\text { toria de Valles, p.91. }\end{array}$ \\
\hline 1808 & 24.238 & 79 & $6.488^{*}$ & 21 & AGI, México, leg.2376 \\
\hline 1819 & 21.645 & 71 & 8772 & 29 & $\begin{array}{l}\text { Isabel Monroy, Pueblos, misiones y presidios } \\
\text { de la intendencia de San Luis Potosí, San Luis } \\
\text { Potosí, México, Archivo Histórico del Estado, } \\
\text { 1991, pp 78-145. }\end{array}$ \\
\hline 1826 & 51.322 & 82 & 11.014 & 18 & $\begin{array}{l}\text { "Noticias estadísticas", en AHESLP, Secretaría } \\
\text { General de Gobierno, varios legajos y expe- } \\
\text { dientes. }\end{array}$ \\
\hline
\end{tabular}

* Únicamente se incluyen las castas: mulatos, negros, lobos, etc.

El Colegio de México, 1972, pp.460-480. Para las Huastecas las cifras de negros de M. L. Herrera Casasús, Presencia y esclavitud, pp.62-71; I. Monroy, Pueblos, misiones y presidios, pp.78-145. 
Tabla 3: Población de la Huasteca potosina a partir de informes religiosos, segunda mitad del siglo XVIII

\begin{tabular}{|c|c|c|c|c|}
\hline Años & Indios & \% & No indios & \% \\
\hline Siglo XVII & 9.040 & $97 \%$ & 272 & $3 \%$ \\
\hline 1748 & 11.376 & $85 \%$ & 1.928 & $15 \%$ \\
\hline $1760-1761$ & 13.776 & $97 \%$ & 364 & $3 \%$ \\
\hline 1778 & 6.121 & $67 \%$ & 2.995 & $33 \%$ \\
\hline 1787 & 15.247 & --- & - & \\
\hline 1791 & 8.147 & $\cdots$ & - & $43 \%$ \\
\hline 1793 & 9.910 & $57 \%$ & 7.341 & $31 \%$ \\
\hline 1796 & 13.070 & $69 \%$ & 5.756 & $38 \%$ \\
\hline 1798 & 11.393 & $62 \%$ & 6.801 & $35 \%$ \\
\hline 1800 & 14.130 & $65 \%$ & 7.652 & $30 \%$ \\
\hline 1801 & 8.094 & $70 \%$ & 3.472 & $23 \%$ \\
\hline 1820 & 15.768 & $77 \%$ & 4.665 & \\
\hline
\end{tabular}

Fuentes: Siglo XVII: Agustín de Vetancurt, Teatro mexicano. Descripción breve de los sucesos ejemplares, históricos, políticos, militares y religiosos del Nuevo Mundo de las Indias, México, Ed. Porrúa, 1982 [1698], pp.91-94. 1748: "Noticias de las Misiones de Tampico de fray Jacobo de Castro. 1748", en C. González, La Evangelización en Tamaulipas, pp.357-370. 1760-1761: "Informes que por mandato de sus prelados superiores hicieron los misioneros de la Custodia de San Salvador de Tampico sobre la fecha de fundación, situación geográfica, número de familias y estado de sus misiones", en BN, Fondo Franciscano, 43/ 987.1, ff.1-28v. 1778: "Relación del estado actual de las misiones de Tampico. 1778", en C. González, La Evangelización en Tamaulipas, pp.403-429. 1787: Informe del Corregidor de Valles para las misiones”, en AGN, Californias, vol.29, ff.176182v. 1791: "Razón del número de indios que en fin del año próximo anterior de 1791 resultaron existen en cada una de las misiones de la Provincia de San Luis Potosí”, en AGN, Californias, vol.29, ff.254-254v. 1793: Revilla Gigedo, Conde de, Informe sobre las Misiones -1743-e Instrucción Reservada al Marqués de Branciforte -1794-, México, Ed. Jus, 1966, pp.91-102. 1796: "Noticia de las Misiones que ocupan los Religiosos de la orden de Sn. Francisco de México sus progresos en los año de 94 y $95 \ldots$ y total de almas con distinción de clases, y sexos [Misiones de San Francisco de México]", en AGN, Californias, vol.29, f.296; "Noticia de las Misiones que ocupan los Religiosos de N.P.s. Francisco en dicha jurisdicción sin progresos en los años de 1795 y $1796 . . . "$, en AHESLP, Intendencia, 1796-1799.1 (16), exp.7, f.5. 1798: "Noticia de las misiones que ocupan los religiosos de la regular observancia de N.S.P. San Francisco... en los años de 1797 y $1798 \ldots$ total de almas, con distincion de clases y sexos [Misiones de la Custodia de San Salvador de Tampico]", en wBS 1394; "Noticia de las Misiones que ocupan los Religiosos de N.s.P.s. Francisco en dicha jurisdiccion: sus progresos en los años de 1797 y 1798...total de Almas, con distincion de clases y sexos [Misiones de la jurisdicción de Villa de Valles], wBS 1394; "Noticia de las Misiones que ocupan los Religosos de S. Francisco de dicha Provincia... sus progresos en los años de 1797 y 1798... , total de Almas con distincion de clases y sexos [Misiones de la Custodia de Rioverde]”, en WBS 1394. 180o: "Noticia de las Misiones que ocupan los Religiosos de N.P.s. Francisco... años de 1799 y 1800...". 1801: Ernesto de la Torre Villar, "Erección de obispados en el siglo XviII. El obispado de Valles", en Estudios de Historia Novohispana, vol. III, México, unAM, 1970, p. 226. 1820: "Visita de Villa de Valles", en AGN, Bienes Nacionales, vol.1182, exp.11. 


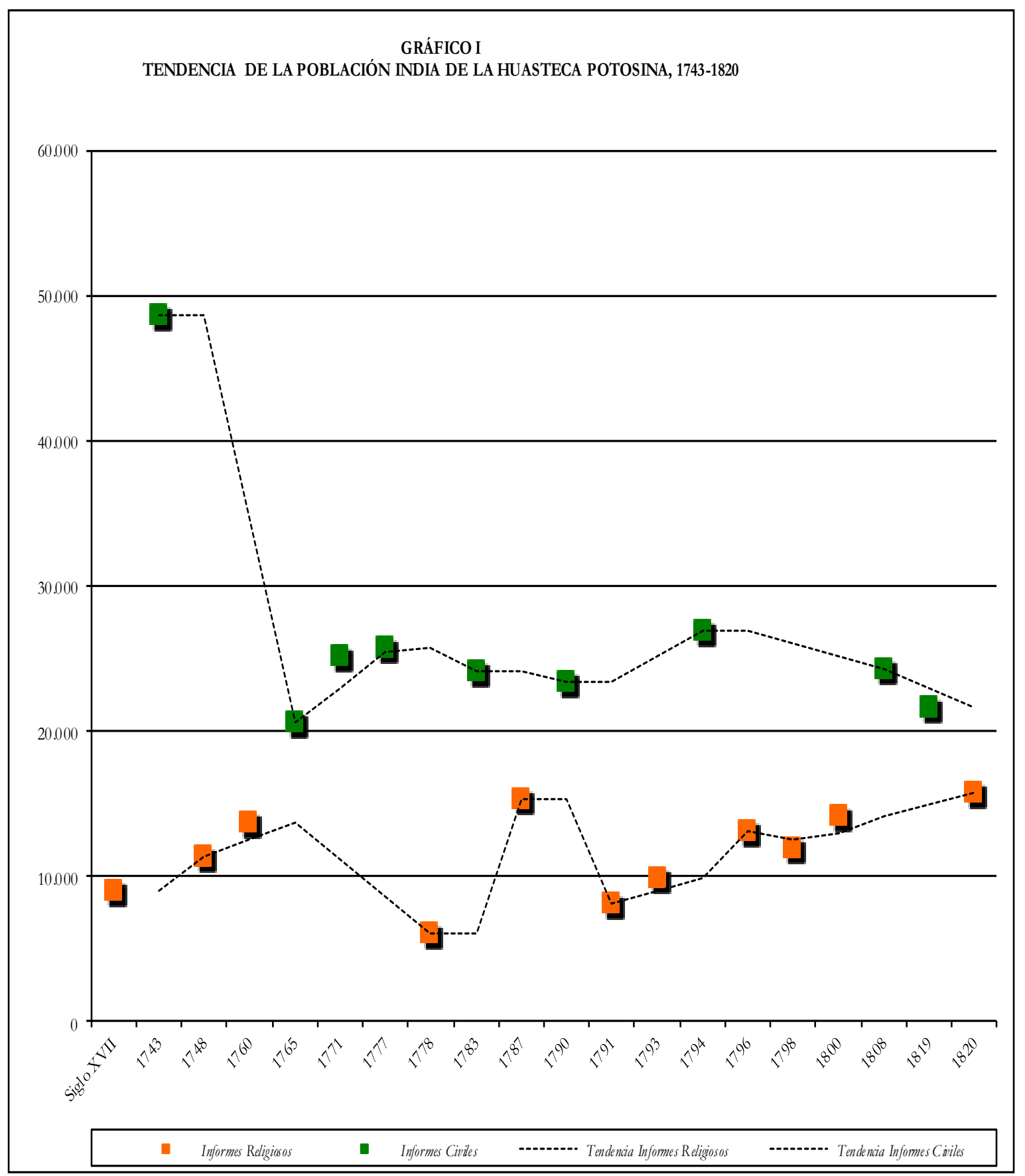




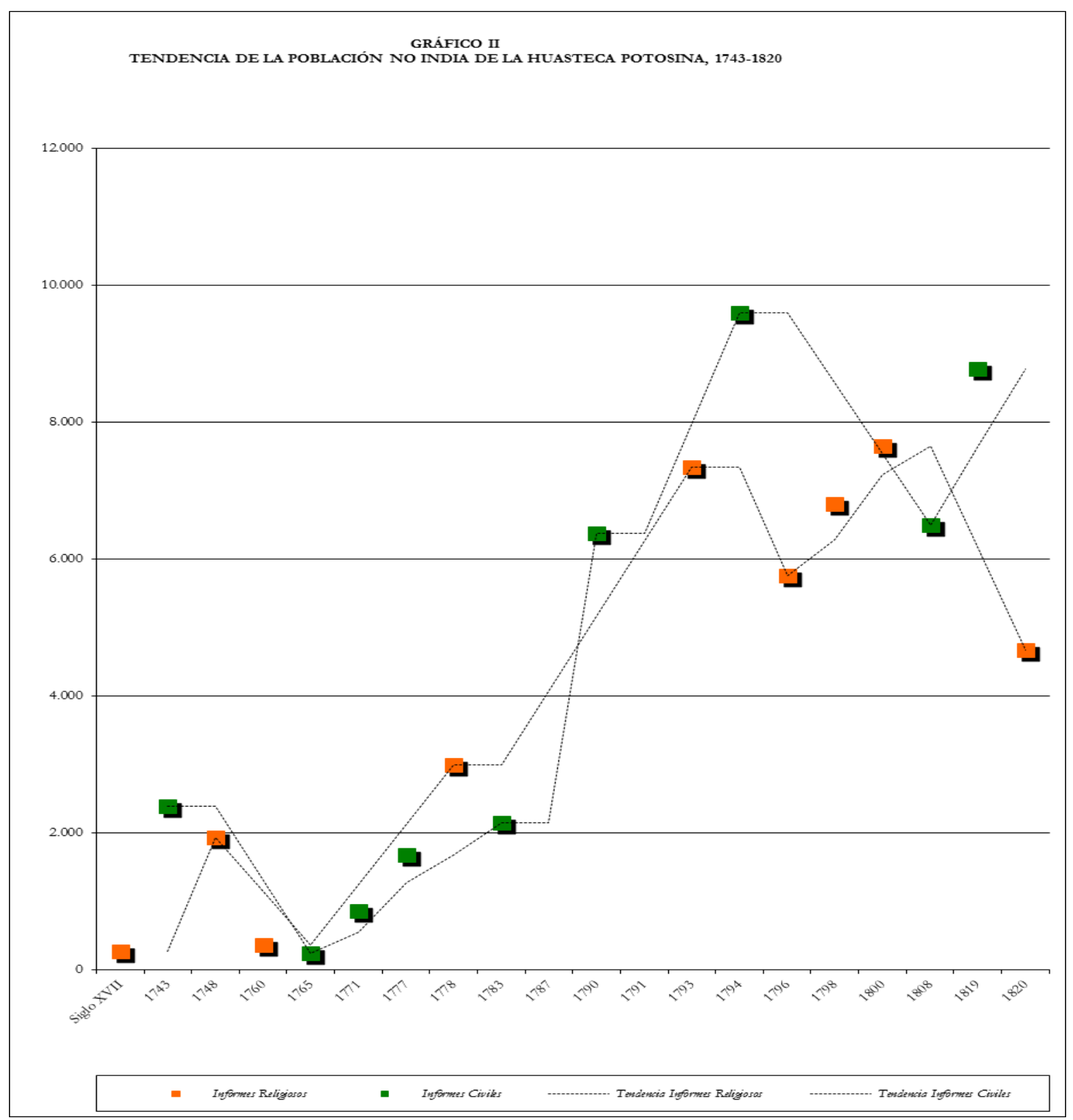


Hay que advertir que las Huastecas no se han podido inscribir en las regiones de crecimiento acelerado, moderado o estancamiento en los siglos XVII y XVIII, ${ }^{51}$ porque no se ha estudiado ni comparado los cambios poblacionales de la región. La dinámica demográfica que se presenta se hace a partir de dos puntos de vista como se menciona en el párrafo anterior.

Lo que se aprecia en las tendencias de la población india a partir de los informes es que desde el siglo XVII hasta la década de los setenta del siglo XVII sufrió una pérdida importante de personas. A pesar que en el gráfico I parece que no existe una correspondencia, en realidad, los informes religiosos informan del periodo de crecimiento de las misiones de 1748 a 1760 . Lo que muestran los informes civiles de 1743 y 1765 es la percepción de la gran caída demográfica de mediados del siglo. Se puede suponer que la diferencia entre las dos tendencias es por el tipo de información que proporcionan. Tampoco hay correspondencia a partir de la década de los setenta hasta principio de los noventa. Los informes civiles muestran una lenta recuperación, mientras que los religiosos un decrecimiento, en ciertos años, de población.

De la década de los noventa a 1820 se encuentra de nuevo correspondencia y crecimiento de población. En este período el complemento de los informes religiosos (1796 a 1800) permiten observar el alza en la población india y el decrecimiento al final de este periodo con un alza en 1820, mostrado en el informe civil. ${ }^{52}$

Con el gráfico de la población no india no hay mayor problema. Existe correspondencia clara de los informes civiles y religiosos. La disparidad que se muestra al principio del siglo XIX, adelantando, no corresponde a la formación de los informes, sino a otro tipo. Para mayor precisión en la tabla 4 se muestran estos cambios.

51 Charles Gibson, Los aztecas bajo el dominio español (1519-1810), México, Siglo XXI, 1996, pp.140-141; A. Molina del Villar, La Nueva España, pp.35-46; A. Ouwennel, Ciclos interrumpidos, pp.212-219.

${ }^{52}$ El trabajo de Elsa Malvido, "Factores de despoblación de reposición de la población de Cholula en la época colonial (1641-1810)", en Elsa Malvido y Miguel Ángel Cuenya (comps.), Demografía histórica de México: siglos XVI-XIX, México, Instituto Mora/Universidad Autónoma Metropolitana, 1993, es una clara muestra del uso de las series de bautismos, matrimonios y defunciones, en los que se puede entender la tendencia de la población por periodos y encontrar las causas inmediatas (epidemias, endemias, desastres, migración). Construir series para la Huasteca potosina tiene dos problemas: el primero es localizar los libros. De acuerdo con María Luisa Herrera Casasús, Misiones de la Huasteca potosina. La custodia del Salvador de Tampico época colonial, México, Programa de Desarrollo Cultura de la Huasteca-Instituto de Cultura de San Luis Potosí/CONACULTA, 1999, pp.115126, existen algunos libros de las misiones en las parroquias. Los mormones cuentan con una amplia biblioteca de microfilms de los registros parroquiales de todas las Huastecas y las fichas pueden consultarse en www.familysearch.org. 
Tabla 4: Crecimiento y decrecimiento de la población de la Huasteca potosina, 1743-1820*

\begin{tabular}{|c|c|c|c|c|}
\hline \multirow{2}{*}{ Periodos } & \multicolumn{2}{|c|}{ Informes civiles } & \multicolumn{2}{|c|}{ Informes religiosos } \\
\hline & Indios & No indios & Indios & No indios \\
\hline $1743-1765$ & $-54.11 \%$ & $-90.18 \%$ & - & - \\
\hline $1748-1760 / 61$ & - & - & $+21.09 \%$ & $-81.12 \%$ \\
\hline $1760 / 61-1778$ & - & - & $-55.56 \%$ & $+722.80 \%$ \\
\hline $1765-1771$ & $+21.77 \%$ & $+264.95 \%$ & - & - \\
\hline $1771-1777$ & $+2.07 \%$ & $+96.95 \%$ & - & - \\
\hline $1777-1783$ & $-6.07 \%$ & $+27.34 \%$ & - & - \\
\hline $1778-1787$ & - & - & $+149.09 \%$ & - \\
\hline $1783-1790$ & $-2.77 \%$ & $+197.38 \%$ & - & - \\
\hline $1787-1791$ & - & - & $-46.56 \%$ & - \\
\hline $1790-1794$ & $+11.41 \%$ & $+46.18 \%$ & - & - \\
\hline $1791-1793$ & - & - & $+21.63 \%$ & - \\
\hline $1793-1796$ & - & - & $+31.88 \%$ & $+0.61 \%$ \\
\hline $1794-1808$ & $-7.25 \%$ & $-30.32 \%$ & - & - \\
\hline 1796-1798 & - & - & $-8.75 \%$ & $+9.84 \%$ \\
\hline $1798-1800$ & - & - & $+30.34 \%$ & $+12.90 \%$ \\
\hline $1800-1820$ & - & - & $+1.43 \%$ & $-49.07 \%$ \\
\hline $1808-1819$ & $-7.25 \%$ & $+35.20 \%$ & - & - \\
\hline
\end{tabular}

* La metodología fue tomar las cifras de población de los distintos informes y establecer la diferencia porcentual de los años inmediatos.

Las causas del crecimiento y decrecimiento del cuadro son de varios de tipos y muestran generalidades a partir de las cifras. En el periodo de 1743 a 1760-61 se aprecia la baja de la población india y no india de la Huasteca potosina. Esto corresponde a la fundación de la Colonia del Nuevo Santander, como ya hemos referido. La consecuencia del decrecimiento demográfico es que los indios pames que se encontraban dispersos en el territorio se tomaron como colonizadores y "esclavos" para la colonia. ${ }^{53} \mathrm{Al}$ confundirlos con indios "bárbaros", de acuerdo con las fuentes y conveniente para los españoles, se tomó población de La Palma para ser llevada a Guadalcázar, San Luis, La Sauceda y la Colonia. De la última se fundaron Santa María Igollo y la Villa de Santa Bárbara con pames, y la Villa de Nuestra Señora de Soledad de Canoas, antes conocida como Tambuanchin. ${ }^{54}$ Para el grupo no

53 "Informes [del coronel José de Escandón] al virrey [marqués de Cruillas] sobre la visita y diligencias que practicó el remitente en la Custodia de San Salvador de Tampico y en la de Río Verde [México] 9 de septiembre de 1765", en BN, Fondo Franciscano, 43/ 991.2, f.5v.

${ }^{54}$ Identificar la cantidad aproximada de indios que fueron llevados como colonizadores o esclavos es difícil de establecer por la escasez de fuentes. Lo mismo sucede para establecer la cantidad de indios que fueron cambiados por ganado y llevados como esclavos a la Antillas en la segunda mitad del siglo XVI, M.L. Herrera Casasús, Presencia y esclavitud, pp.7-14. 
indio la oferta fue distinta y es probable que la causa del crecimiento acelerado de 1760/ 61-1778 fuera por la oferta de tierras y beneficios en el comercio y la producción. ${ }^{55}$ Del periodo de 1765 a 1796 hubo constantes cambios; sin embargo, hay un crecimiento moderado en el grupo indio, y uno muy acelerado en el no indio. Aunque las causas no se han podido identificar es probable que las tierras abandonadas de los indios fueran tomadas por "nuevos" colonos o migrantes de distintas regiones que aprovecharon las grandes extensiones para fundar algún tipo de localidad.

Otras causas del decrecimiento de la población fueron las epidemias y fenómenos naturales a los que se ha hecho referencia para explicar las distintas formas de movilidad de los indios. El caso más temprano en el siglo XVIII, fue en la década de los treinta, cuando se dio el "despoblamiento momentáneo" del pueblo de Tanquian por las "pestes" que lo azotaron, sin embargo, posteriormente volvieron al sitio en el que se asentaron. ${ }^{56} \mathrm{El}$ ejemplo más significativo corresponde a las décadas de los setenta y ochenta en la que varios pueblos fueron relevados del tributo.

En la década de los cincuenta hubo dos inundaciones en Valle del Maíz, en 1751 y 1757, lo que ocasionó en el primer año 29 muertes, y en el segundo la refundación de la localidad en otro sitio. ${ }^{57} \mathrm{El}$ fenómeno anterior no se compara con los que sucedieron en las décadas del sesenta, setenta y ochenta. Desde 1769 hasta 1775 se registró en la Huasteca potosina esterilidad en los campos, heladas, y falta de agua. ${ }^{58}$ Como no es posible seguir la secuencia se pueden encontrar casos aislados. En Tamuín hubo plaga de langosta aproximadamente en 1768, en Valles entre 1771 y 1776 , y en general en la Huasteca en $1775 .{ }^{59}$ Una plaga de langosta azotó a las Huastecas, afectando a los partidos de Huejutla, Tantoyuca, Papantla, Huauchi-

55 "Relación del estado actual de las misiones de Tampico. 1778”, en C. González, La Evangelización de Tamaulipas, pp.416, 419-420; J.J. García, Informe privado, pp.12-13; Agustín López de la Cámara Alta, Descripción general de la nueva colonia de Santander, México, Imprenta "Beatriz de Silva", 1946, p. 24; J. Meade, Historia de Valles, p.77; P. Gerhard, La frontera norte, pp.450-451.

56 "El virrey manda a la justicia de la Villa de Valles, notifique a Antonio González deje libre a los naturales el uso de sus tierras, para que los indios que estuvieren ausentes se vuelvan y restituyan a su pueblo, cumpliendo con las reales leyes y ordenanzas, celando la indemnidad de los sembrados de los indios, pena de 500 pesos. Villa de los Valles”, en AGN, Indios, vol.54, exp.58, ff.63v-64. Debe notarse que el año de este manuscrito, 1795, es muy cercano a la gran epidemia de Matlazahuatl (1736-1739) que azotó a toda la Nueva España y que en la Huasteca no se ha documentado, A. Molina del Vllar, La Nueva España, passim.

${ }^{57}$ AGN, Historia, vol.72(2), f.354v.; J. Mandeville, La jurisdicción, p.106.

${ }^{58}$ AGI, Audiencia de México, leg.2103.

59 "Relación del estado actual de las misiones de Tampico.1778”, en C. González, La Evangelización en Tamaulipas, p.413; AGI, Audiencia de México, leg.2103. 
nango y Chicontepec en 1795, que junto con la "esterilidad de los campos" y la anticipación de las heladas, de 1771 a 1776, obligó a los indios a "salirse arrastrando, a los montes". ${ }^{60}$ La consecuencia administrativa de no contar con los recursos de subsistencia fue que se relevara de tributo a los indios para que no se dispersaran. Se concedieron relevas a 18 localidades como Valles, Tamazunchale, Tanzab, Tanlacum, Tamitas y el barrio de San Miguel.61

De igual magnitud fue la sequía de 1785-1786 que se describe por la falta de lluvias en la tercera de junio y la helada del 27 de agosto al 3 de septiembre. ${ }^{62}$ En la jurisdicción de la Villa de los Valles el caso parece que fue distinto. En 1785 hubo dos huracanes, uno de aguas y el otro de aires del 7 de septiembre que duró "doze horas y tantas" que derribó las milpas y casas, que obligó a buscar a los indios a buscar sustento en otro lado, principalmente las serranías. ${ }^{63}$ A pesar de no poder definir cada uno de ellos coincidió con el periodo de tonalmil, arrasando las "milpas que estaban unas en razón, y otras gilotiando", además de pudrirse el maíz por el exceso de agua. ${ }^{64}$ La sequía se incrementó y causó que se relevaran de tributo a

${ }^{60}$ De Villa de los Valles se relevaron de tributo a 18 pueblos, entre ellos estaban Tansab, Tanlacum y Tamitas con su barrio de San Miguel (5 de mayo de 1778), Tamazunchale y sus pueblos (enero y marzo de 1775), en AGI, Audiencia de México, leg.2103; "El virrey concede relevar de tributos por el tiempo que se expresa, a los gobernadores de la misión de la Purísima Concepción de Tamitas y barrio de San Miguel, jurisdicción de Villa de Valles, para que puedan recuperarse de las enfermedades y demás miserias", en AGN, Indios, vol.65, exp.280, ff.312-312v; Coxcatlán también sufrió de la plaga de langosta de "chapulines" en 1794, en AGN, Historia, vol.72 (2), f.353; J. Mandeville, La jurisdicción de la Villa, p.109.

${ }^{61}$ AGI, Audiencia de México, leg.2103; "Importe del ramo de Reales Tributos y Servicio Real de indios, de pueblos de mulatos y laboríos del año de 1775”, en AGI, Audiencia de México, leg.2105.

62 Rodolfo Pastor, "Introducción", en Enrique Florescano (comp.), Fuentes para la historia de la crisis agrícola de 1785-1786, vol.I, México, AGN, 1981, pp.31-34.

63 "El virrey concede releva a los naturales del pueblo de Aquismón de la jurisdicción de Villa de Valles, de la paga de tributos del año vencido", en AGN, Indios, vol.67, exp.96, ff.106-107; "El virrey concede releva a los naturales de las cabeceras y pueblos contenidos en la respuesta del señor fiscal insertas, pertenecientes a la Villa de Valles, del tributo vencido en el año próximo pasado y manda que al efecto se le libre este despacho", en AGN, Indios, vol.67, exp.24, ff.30-32; "El virrey conde de Gálvez concede releva a los naturales del pueblo de San Juan Tamazunchale y su anexo de Santiago Tlamaxac, de la paga de tributo del año 85 y manda se ejecute lo que se le previene”, en AGN, Indios, vol.67, exp.83, ff.90-91v; “Carta de julio de 1789”, en AHESLP, Intendencia, leg. 1771, exp. único.

64 "El virrey conde de Gálvez concede releva a los naturales del pueblo de San Juan Tamazunchale y su anexo de Santiago Tlamaxac, de la paga de tributo del año 85 y manda se ejecute lo que se le previene", en AGN, Indios, vol.67, exp.83, f.91; "El virrey concede releva a los naturales del pueblo de Aquismón de la jurisdicción de Villa de Valles, de la paga de tributos del año vencido", en AGN, Indios, vol.67, exp.96, f.106. 
los pueblos de la jurisdicción de Villa de los Valles sin que se pudiera contener la huida de los indios a las serranías. ${ }^{65}$

Los desastres y epidemias continuaron al final del siglo XVIII. Para finalizar la década de los ochenta en Tanlajás y San Antonio hubo una helada que fue acompañada de plaga de ratones. ${ }^{66}$ En 1788 y 1789 se presentó una helada que afectó a los pueblos de Tanlajás y San Antonio causando que se perdieran los sembrados y los cañaverales. ${ }^{67}$

El relativo crecimiento de la población del siglo XviII también fue mermado por epidemias, como apenas se mencionó arriba. La más temprana conocida fue en 1735 en la localidad de Tanquián. Le siguió la de 1762, de viruela, en la que murieron "muchisimos". ${ }^{68}$ En 1770 la peste afectó a El Sauz. ${ }^{69}$ La de 1777 no se ha identificado, ni los pueblos que afectó. ${ }^{70}$ En 1796 una epidemia de viruela que se propagó desde Perú y entró a la Nueva España por Veracruz y Oaxaca afectando a la Huasteca potosina en un periodo indeterminado, causando una cifra aproximada de 3 395 muertes en la jurisdicción de Villa de los Valles. Podemos considerar que los fallecimientos pudieron ser más, ya que no se contaron a los que vivían en las serranías o al ser enterrados sin saber la causa de muerte..$^{71}$

65 "El virrey concede releva a los naturales de las cabeceras y pueblos contenidos en la respuesta del señor fiscal insertas, pertenecientes a la Villa de Valles, del tributo vencido en el año próximo pasado y manda que al efecto se le libre este despacho", en AGN, Indios, vol.67, exp.24, ff.30-32; "Carta de julio de 1789", en AHESLP, Intendencia, leg.1771, exp. único.

${ }^{66}$ AGN, Historia, vol.72, exp.2, ff.348v, 353; J. Mandeville, La jurisdicción de la Villa, pp.105, 110.

${ }^{67}$ AGN, Historia, vol.72 (2), ff.348v, 353; J. Mandeville, La jurisdicción de la Villa, pp.105-110.

${ }^{68}$ AGN, Historia, vol.72(2), f.350; J. Mandeville, La jurisdicción de la Villa, p.107.

69 "Carta de fray Francisco Ibañez, custodio de Tampico, al provincial Fray Manuel de Nájera, sobre la conducta que observan algunos religiosos de su custodia. Misión de Tanlajax, 9 de noviembre de 1770", en BN, Fondo Franciscano, 43/ 996.4, f.12; "Relación del estado actual de las misiones de Tampico. 1778”, en C. González, La Evangelización de Tamaulipas, pp.417, 419.

70 "Importe del ramo de Reales Tributos y Servicio Real de indios, de pueblos de mulatos y laboríos del año de 1777", en AGI, Audiencia de México, leg.2105.

71 "Carta de Agustín de [...] y Ugarte al Intendente de San Luis Potosí. Tancanhuitz 13 de diciembre de 1799", en AHESLP, Intendencia, 1796-1799.1 (16), exp.2, ff.19-20v.; "Noticia del número de Personas que padecieron viruelas naturales é inoculadas en la epidemia de los años de 1798 y 1799 con expresión de las que fallecieron de una y otra clase [Partido de la Villa de Santiago de los Valles]", en AHESLP, Intendencia, 1796-1799.1 (16), exp.2, f.30; "Noticia de las Misiones que ocupan los Religiosos de N.S.P.S. Francisco en dicha jurisdiccion: sus progresos en los años de 1797 y 1798: numeros de ministros que las sirven, sinodos que gozan, y total de Almas, con distincion de clases y sexos [Mi- 
Siguiendo con las tendencias en los cambios de población para última década del siglo XVIII y las dos primeras del XIX, como se mencionó, hubo un cambio en las tendencias de población. La explicación del cambio está relacionada con la estructura administrativa de los pueblos indios. A partir de 1812 se crearon los ayuntamientos y los grupos de no indios aprovecharon la nueva estructuración administrativa para ingresar a cargos políticos que hasta esa fecha no les había sido posible alcanzar. ${ }^{72}$

Esta tabla explica por qué el descenso de población en las castas. Aunque se presentan cuadros generales, es claro que la población española crece de forma aritmética a partir del grupo de edad de 16 a 25 años y así los siguientes. Las razones, se puede suponer, es que a partir de la identificación con un grupo racial podían compartir, tener membresía, a los espacios políticos y públicos y así controlar al resto de la población, territorio y la riqueza que se generara de las localidades. En cambio, en los dos últimos grupos de edad de los indios la población decrece. Para los otros grupos de edad, personas de hasta 16 años, parece que convino "colocar" a los niños cercanos a los españoles para que a partir de la "cuna" pudieran acceder al poder a lo largo del tiempo. ${ }^{73} \mathrm{Si}$ se necesitan más particularidades se puede afirmar que las localidades que se convirtieron en ayuntamientos en 1812 tuvieron cambios demográficos significativos como en Villa de los Valles, Valle del Maíz, Aquismón, Huehuetlán, Coxcatlán, Tampamolón, Tancanhuitz y San Antonio.

siones de la jurisdicción de Villa de Valles]”, en WBS 1394. P. Gerhard, La frontera norte, p. 450, en especial la nota 33 .

\footnotetext{
72 A. Escobar Ohmstede, "Los pueblos de indios", pp.128-129; del mismo autor De la costa, pp.151156. John K. Chance, "On the Mexican Mestizo", in Latin American Research Review vol.IV, n. ${ }^{\circ}$, Durham, Duke University Press, 1979, p.163; Michael T. Ducey, "Indian Communities and Ayuntamientos in the Mexican Huasteca: Sujeto Revolts, Pronunciamientos and Caste War", in The Americas vol.57, n. ${ }^{\circ}$ 4, Berkeley, Academia de Historia Franciscana de América, 2001, pp.530-537; del mismo autor, "Indios liberales y liberales indigenistas: ideología y poder en los municipios rurales de Veracruz, 1821-1890", en A. Escobar Ohmstede y L. Carregha Lamadrid (coords.), El siglo XIX, pp.112-136.
}

${ }^{73}$ El caso de Perú colonial es rico en estos ejemplos, Karen Spalding, "Social Climbers: Changing Patterns of Mobility among the Indians of Colonial Peru", in Hispanic American Historical Review vol.50, n. ${ }^{\circ}$ 4, Durham, Duke University Press, 1970, pp.651-653. 
Tabla 5: Proporción de los grupos de edad de la Huasteca potosina, 1790 y 1819

\begin{tabular}{|c|c|c|c|c|c|c|c|c|}
\hline \multirow[b]{2}{*}{$\begin{array}{l}\text { Grupos } \\
\text { de edad }\end{array}$} & \multicolumn{4}{|c|}{1790} & \multicolumn{4}{|c|}{1819} \\
\hline & do & do & d゚ $\frac{\tilde{J}}{\tilde{\hbar}}$ & o & o० & oㅇ & $\therefore \frac{n}{\tilde{J}}$ & 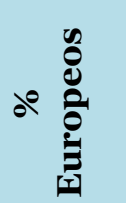 \\
\hline$>-7$ años & 81.59 & 6.59 & 11.81 & 0 & 75.83 & 19.99 & 4.16 & 0 \\
\hline $7-16$ & 72.36 & 11.30 & 16.32 & 0 & 75.57 & 21.95 & 2.47 & 0 \\
\hline $16-25$ & 75.23 & 9.47 & 15.27 & 0.01 & 68.24 & 29.69 & 2.04 & 0.01 \\
\hline $25-40$ & 82.12 & 6.30 & 11.41 & 0.15 & 73.49 & 24.53 & 1.96 & 0 \\
\hline $40-50$ & 76.63 & 8.85 & 14.36 & 0.15 & 66.50 & 30.95 & 2.51 & 0.02 \\
\hline $50-<$ & 76.04 & 8.83 & 14.93 & 0.19 & 62.54 & 34.97 & 2.25 & 0.22 \\
\hline
\end{tabular}

Fuentes: H. Castro, Censo de población, pp.71-102; I. Monroy, Pueblos, misiones y presidios, pp.78145 .

Hasta este punto se han analizado las generalidades de la población. Se estudió el crecimiento y decrecimiento demográfico por las consecuencias de la fundación de la Colonia del Nuevo Santander; las diversas epidemias, sequías, huracanes e inundaciones que afectó a las localidades de la Huasteca y de sus grupos étnicos de distinta forma; por último fue posible conocer los cambios en la población cuando se fundaron los ayuntamientos en localidades, pueblos, que tenían una o varias referencias espaciales constantes. Toca ahora hablar de la estructura de las localidades a partir de distintos aspectos como ocupación, proporción de personas en localidades o por lo menos conocer la composición por habitantes, el número de individuos por familia, y la localización geográfica de los grupos étnicos (indios, españoles, castas).

Pocos son los estudios que han tratado de la estructura ocupacional del siglo XVIII. Por la escasa existencia de información se ha adoptado utilizar el censo de Revillagigedo para conocer la división social en distintas localidades, en especial las ciudades. ${ }^{74}$ Como en la Huasteca potosina no existieron las ciudades y mucho me-

\footnotetext{
${ }^{74}$ D. Brading, "Grupos étnicos", pp.460-480; John Chance and William B. Taylor, "Estate and Class in a Colonial City: Oaxaca in 1792", in Comparative Studies in Society and History vol.xIX, n. ${ }^{\circ}$, Cambridge, Cambridge University Press, 1977, pp.454-487. Un estudio general de la Nueva España utilizando la información del censo de Revillagigedo en Sherburne F. Cook, "La población de México en 1793", en E. Malvido y M.Á. Cuenya (comps.), Demografía histórica de México, pp.141-159. S. Cook y W. Borah, Ensayos sobre historia de la población, tomo I, pp.59-60.
} 
nos ha sido posible localizar cada uno de los puntos geográficos, es por lo que se ha realizado el análisis a partir de las jurisdicciones y cada una de las localidades. ${ }^{75}$

Aquí no se utilizará el censo militar de 1792 que no ha sido localizado en los archivos, sino, el de 1790 que presenta una tabla pormenorizada de la estructura poblacional y ocupacional de cada una de las jurisdicciones de los pueblos. ${ }^{76} \mathrm{En}$ términos generales la Huasteca potosina tenía 5866 tributarios de los cuales Tancanhuitz, Coxcatlán, Tamazunchale y Huehuetlán tenían la mayoría $(870,801,664$ y 608, respectivamente) y las localidades con más de 200 eran Villa de los Valles, Valle del Maíz, Aquismón, Axtla, y San Antonio (este último con 401). Si se compara con la información de la distribución de la producción, en el apartado anterior, se verá que en las localidades con mayor número de tributarios había pocas haciendas, ranchos y estancias; en cambio, donde hay un número mayor de 200 tributarios son los sitios con mayor número de estas localidades. Esto significa que la producción indígena se concentraba en el corazón de jurisdicción y que desde estos puntos el control, en su mayoría, en manos de los nahuas que tendían un corredor hacia la jurisdicción de Huejutla pasando por Tamazunchale, dejaban al resto de los indios, en especial de Valles y Valle del Maíz, en los trabajos agrícolas de las haciendas, y que en total de la Huasteca sumaban 689. Sin embargo, que se registraran 5 comerciantes, en la última localidad (Valle del Maíz), da una idea de la importancia de la localización, ya que es probable que fuera punto de salida de mercancías hacia la ciudad de San Luis Potosí.

La desventaja de utilizar el censo anterior es que no nos permite entender cómo se distribuía la población en la jurisdicción de una localidad ya que no se mencionan los sitios que se tomaron en cuenta para obtener los totales, ni la diferencia en cifras de cada una de las unidades espaciales. Para entender la estructura poblacional de las jurisdicciones hay algunos padrones, como el de Tamuín de 1820, que permiten entender dónde se encontraban las personas, el número de familias (en algunos casos), y la composición étnica. ${ }^{77}$ Se debe advertir que esta información es un instante en el tiempo. Si en las visitas pastorales del mismo año se hubieran elaborado estos mismos padrones se podría comparar distintas jurisdicciones.

Lo primero que se observa de la jurisdicción es que los 447 indios (48.47\%) y 475 de no indios (51.51\%) se distribuyen equitativamente. Para hacer más puntual

\footnotetext{
75 A. Escobar Ohmstede, "La estructura socioeconómica”, pp. 5-36.

${ }^{76}$ H. Castro, Censo de población, pp.73-102

77 "Visita de Tamuy", en AGN, Bienes Nacionales, vol.1182, exp.17; S. Cook y W. Borah, Ensayos sobre historia de la población, t.I, pp.63-64.
} 
el análisis se aprecia en el cuadro que la mayoría de la población vivía en las haciendas y ranchos (81.77\%), el resto en la misión y el pueblo (18.21\%).

La minoría de los indios, 120 (26.84\%), se encontraban en la misión. El resto, 327 (73.15\%) en las rancherías de las haciendas de Taninul y El Limón. En el padrón se aprecia que la primera tenía una fuerza de trabajo flotante. Estos indios, 178 (39.82\%), entraban y salían de la hacienda sin dificultad. Mientras que los de la hacienda de El Limón, 45 (10.06\%), se ubicaban en las rancherías y estancias. El grupo de no indios presenta un patrón de asentamiento semejante. Los 48 (10.10\%) se encontraba en el pueblo, mientras que en las haciendas y ranchos, 427 (89.89\%), la gran mayoría.

Hasta que se encuentren y analicen otros padrones no se podrá sugerir con más detalle la estructura de las jurisdicciones de las localidades de la Huasteca potosina y poder ubicar, por lo menos en términos generales, las diferencias poblacionales entre los grupos étnicos, ni su ubicación.

\section{Consideraciones finales}

El mostrar tendencias generales de casi 100 años en torno a la población indígena y la que no lo era, nos ha permitido observar la manera en que los individuos se ubicaban en el espacio social estudiado, así como observar los incrementos y decrecimientos de los actores con base en la comparación de los informes que generaron las autoridades civiles y eclesiásticas.

La existencia de diversos tipos de localidades y la distribución de individuos que en ellas había, nos lleva a contrastar y analizar "manchones" de población ubicados, en cierta forma, a partir del entorno y se modificaron a lo largo del siglo XVIII y principios del siglo XIX. Por ejemplo, la creación de algunas de las misiones franciscanas en tierras de haciendas, sin duda, le otorgó a los propietarios privados fuerza de trabajo permanente, y que por lo que se aprecia muy valorada, ya que al ser considerados los pueblos de la Huasteca potosina como puntos fronterizos, estaban exentos del pago de tributo y por lo tanto no se veían obligados a trabajar fuera de los pueblos con el fin de obtener dinero o bienes para pagar tributo. Sin embargo, con el pasar de los años, las haciendas y ranchos se convirtieron en lugares de asentamiento para individuos de "calidad" indígena o mestiza, debido principalmente, a la paulatina carencia de tierras. Por otro lado, localidades como pueblos y barrios concentraban al pie de la Sierra Madre gran cantidad de individuos que conformaban una sociedad pluriétnica y que estaban distribuidos en el espacio de acuerdo a sus intereses. 
Lo que se ha pretendido mostrar, además de la disparidad de las fuentes, es la estabilidad que presentó la población, aun considerando los fenómenos naturales adversos y las epidemias. Este hecho nos permite destacar que las "rancherías volantes" observadas en Sonora o la desestabilización de los pueblos por la movilidad, como en el caso de Yucatán, no se presentaron totalmente en el espacio social estudiado. Esto no implica que lo podamos considerar como aspectos que también ocurrieron en otro lugares; sin embargo, la pervivencia de los pueblos, aun cuando los barrios se convirtieron en la referencia obligada de una casi "pureza india" frente a cabeceras y propiedades más diversas o pluriétnicas, nos muestran las adaptaciones que realizaron los diversos habitantes, considerando desde un proceso de etnogénesis hasta la confrontación y expulsión de no indios de ciertas localidades.

Todo lo anterior nos permite entender, junto con las necesidades de una cultura material, como las acciones internas y externas que influyeron en la manera en cómo se apropiaban y refuncionalizaban el espacio los diversos actores sociales.

Por el momento, creemos que hemos logrado diferenciar y ubicar en su espacio a cada una de las posibles denominaciones étnicas con el fin de mostrar que lo indio no precisamente indica homogeneidad en las propias fuentes, sino importantes niveles de movilidad y diferenciación interna, ya que no era lo mismo ser identificado como pame o meco a autodefinirse como huasteco o "mexicano". A partir de este hecho las cifras generales pueden observarse con una mayor confiabilidad, ya que la construcción de los niveles micro permitieron acercarnos lo más posible a una realidad histórica que nos enseña que la dispersión, la movilidad voluntaria o forzosa, las epidemias y la etnogénesis no nos es aun comprensible.

\section{Bibliografía}

Aguilar Robledo, Miguel, "Haciendas y condueñazgos en la Huasteca potosina: notas introductorias", en Jesús Ruvalcaba Mercado (coord.), Nuevos aportes al conocimiento de la Huasteca, México, CIESAS/CIHSLP/CEMCA/IPN/UACH/INI, 1998, pp.123151.

Aguilar Robledo, Miguel, "Ganadería, tenencia de la tierra e impacto ambiental en una región fronteriza de la Nueva España: la Jurisdicción de la Villa de Santiago de los Valles de Oxitipia, 1527-1821", en Estudios Geográficos vol.LXIX, n. ${ }^{\circ} 230$, Madrid, Instituto Juan Sebastián Elcano, 1998, pp.5-34.

Blázquez, Carmen, Contreras, Carlos y Pérez Toledo, Sonia (coords.), Población y estructura Urbana en México, siglos XVIII y XIX, México, Instituto Mora/Universidad Veracruzana/Universidad Autónoma Metropolitana, 1996. 
Bracamonte y Sosa, Pedro, La conquista inconclusa de Yucatán: los mayas de la montaña, 1560-1680, México, CIESAS/UQROO/Miguel Ángel Porrúa, 2001 (Colección peninsular, serie estudios).

Brading, David A., "Grupos étnicos; clases y estructura ocupacional en Guanajuato (1792)", en Historia Mexicana vol.xxi, n. ${ }^{\circ} 3$, México, El Colegio de México, 1972, pp.460480 .

Cabrera, Antonio J., La Huasteca potosina. Ligeros apuntes sobre este país, México, Tipografía del "Comercio", 1876.

Calvo, Thomas y López, Gustavo (Coords.), Movimientos de población en el Occidente de México, México, CEMCA/COLMICH, 1988.

Carrasco Pedro, "La transformación de la cultura indígena durante la colonia", en Historia Mexicana vol.xxv, . $^{\circ}$ 2, México, El Colegio de México, 1975, pp.175-203.

Castro Aranda, Hugo, Censo de población de la Nueva España. 179o, México, Secretaría de Programación y Presupuesto-Dirección General de Estadística, 1977.

Cavazos Garza, Israel, et. al., Constructores de la nación: la migración tlaxcalteca en el norte de Nueva España, México, COLSAN/Gobierno del Estado de Tlaxcala, 1999.

Chance, John K., "On the Mexican Mestizo", in Latin American Research Review vol.IV, n. ${ }^{\circ} 3$, Durham, University Duke Press, 1979, pp.153-168.

Chance, John K., Razas y clases de la Oaxaca Colonial, México, INI, 1982 (Colección INI, n. ${ }^{\circ} 64$, Serie Antropología Social).

Chance, John K., La conquista de la Sierra. Españoles e indígenas de Oaxaca en la época de la Colonia, México, CIESAS/IOC/Fondo Estatal para la Cultura y las Artes, 1998 (Colección Etnohistoria, Serie Dishá).

Chance, John K. y Taylor, William B., "Estate and Class in a Colonial City: Oaxaca in 1792”, in Comparative Studies in Society and History vol.XIX, n. ${ }^{\circ}$, Cambridge, Cambridge University Press, 1977, pp.454-487.

Cook Sherburne, F., "La población de México en 1793", en Elsa Malvido y Miguel Ángel Cuenya (comps.), Demografía histórica de México: siglos XVI-XIX, México, Instituto Mora/Universidad Autónoma Metropilitana, 1993, pp.141-159, (Antologías Universitarias). 
Cook, Sherburne F. y Woodrow, Borah, Ensayos sobre historia de la población: México y el Caribe, tomo I, México, Siglo XXI, 1977 (Colección América Nuestra, Serie América Colonizada).

Corboz, André, "El territorio como palimpsesto”, en Diógenes n. ${ }^{\circ} 121$, México, 1983, pp.1536.

Dehouve, Danièle, Cuando los banqueros eran santos. Historia económica y social de la provincia de Tlapa, Guerrero, México, Universidad Autónoma de Guerrero, 2001 (Colección Textos de Investigación).

Ducey, Michael T., "Indian Communities and Ayuntamientos in the Mexican Huasteca: Sujeto Revolts, Pronunciamientos and Caste War", in The Americas vol.57, n. ${ }^{\circ}$, Berkeley, Academia de Historia Franciscana de América, 2001, pp.525-550.

Ducey, Michael T., "Indios liberales y liberales indigenistas: ideología y poder en los municipios rurales de Veracruz, 1821-1890", en Antonio Escobar Ohmstede y Luz Carregha Lamadrid (coords.), El siglo XIX en las Huastecas, México, CIESAS/COLSAN, México, 2002, pp.111-136 (Colección Huasteca).

Escobar Ohmstede, Antonio, "La estructura socioeconómica de las Huastecas en el siglo XVIII. El censo militar de 1791", en La Palabra y el Hombre. Revista de la Universidad Veracruzana n. ${ }^{\circ}$ 96, Veracruz, Universidad Veracruzana, 1995, pp.5-36.

Escobar Ohmstede, Antonio, De la costa a la sierra. Las huastecas, 1750-19oo, México, CIESAS/INI, 1998 (Historia de los pueblos indígenas de México).

Escobar Ohmstede, Antonio, "Los pueblos indios de las Huastecas a través de cien años de historia”, en Manuel Ferrer Muñoz (coord.), Los pueblos indios y el parteaguas de la Independencia de México, México, Instituto de Investigaciones Jurídicas/UNAM, 1999, pp.105-165.

Escobar Ohmstede, Antonio, "El comercio en las Huastecas. Los indígenas y su participación, siglo XVIII", en Jorge Silva Riquer y Antonio Escobar Ohmstede (coords.), Mercados indígenas en México, Chile y Argentina. Siglos XVIII-XIX, México, Instituto Mora/CIESAS, 2000, pp.87-115.

Escobar Ohmstede, Antonio, “Insurgencia y ayuntamientos en las Huastecas”, en Pilar Gonzalvo y Andrés Lira (Coords.), México, 1808-1821. Las ideas y los hombres, México, COLMEX, 2014, pp.133-177.

Escobar Ohmstede, Antonio y Carregha Lamadrid, Luz, "Introducción. El siglo XIX en las Huastecas. Breve balance sobre la 'región' y temas en la historiografía”, en Antonio 
Escobar Ohmstede y Luz Carregha Lamadrid (coords.), El siglo XIX en las Huastecas, México, CIESAS/COLSAN, 2002, pp.13-39 (Colección Huasteca).

Escobar Ohmstede, Antonio, y Rangel S., José Alfredo (coords.), Haciendas, negocios y política en San Luis Potosí, siglos XVIII al XX, México, El Colegio de San Luis, 2011.

Escobar Ohmstede, Antonio, "Estado general de tributos y tributarios, 1805", en Boletín del Archivo General de la Nación, tomo I, n. ${ }^{\circ} 3,3^{\mathrm{a}}$. Serie, México, AGN, 1977, pp.343 .

Fagoaga Hernández, Ricardo A., Circuitos mercantiles de la Huasteca potosina, 17431812, tesis de maestría, COLSAN, 2004.

Familias novohispanas. Siglos XVI al XIX. Seminario de Historia de la familia, México, COLMEX, 1991.

Farris, Nancy M., La sociedad maya bajo el dominio colonial. La empresa colectiva de la supervivencia, Madrid, Alianza Ed., 1992 (Quinto Centenario).

Gallini, Stefania, "Historia, ambiente y política: El camino de la historia ambiental en América Latina”, en Nómadas n. ${ }^{\circ} 30$, Bogotá, Universidad Central, 2009, pp.92102.

García, Joseph Joachin fray, Informe privado contra Escandón, México, Imprenta "Beatriz de Silva”, 1946 (Archivo de la Historia de Tamaulipas, $1^{\text {a }}$. Serie, t. VI). Compilado y editado por Gabriel Saldívar.

García Acosta, Virginia, Pérez Zevallos, Juan Manuel y Molina del Villar, América, Desastres agrícolas en México. Catálogo histórico. Épocas prehispánica y colonial (9581822), t.I, México, FCE/CIESAS, 2003.

García Hernández, Alma, “Alternativas ante las sequías de 1789-1810 en la Villa de Saltillo, Coahuila, México", en Virginia García Acosta (coord.), Historia y desastres en América Latina, vol.2, México, La Red/CIESAS, 1997, pp.148-169.

García Martínez, Bernardo, "Pueblos de Indios, Pueblos de Castas: New Settlements and Traditional Corporate Organization in Eighteenth-Century New Spain”, en Arij Oweneel y Simon Miller (eds.), The Indian Community of Colonial Mexico. Fifteen Essays on Land Tenure, Corporate Organizations, Ideology and Village Politics, Amsterdam, CEDLA, 1990, pp.103-116 (CEDLA Latin America Studies, 58).

García Martínez, Bernardo, "Los caminos del ganado y las cercas de las haciendas. Un caso para el estudio del desarrollo de la propiedad rural en México", en Historia y Grafía n. ${ }^{\circ}$ 5, México, Universidad Iberoamericana, 1995, pp.13-29. 
García Martínez, Bernardo, "Los poblados de hacienda: personajes olvidados en la historia del México rural”, en Alicia Hernández Chávez y Miño Grijalva Manuel (coords.), Cincuenta años de Historia en México. En el Cincuentenario del Centro de Estudios Históricos, vol. I, México, COLMEX, 2001, pp.331-370.

Gerhard, Peter, Geografía histórica de la Nueva España, 1519-1821, México, UNAM, 1986.

Gerhard, Peter, La frontera norte de la Nueva España, México, UNAM, 1996.

Gibson, Charles, Los aztecas bajo el dominio español (1519-1810), México, Siglo XXI, 1996.

González Salas, Carlos, La Evangelización en Tamaulipas. Las misiones novohispanas en la costa del Seno Mexicano (1530-1831), México, Instituto de Investigaciones Históricas/UAT, 1998.

Gortari, Hira de, "Itinerarios en el estudio de las ciudades decimonónicas mexicanas", en Entorno Urbano. Revista de Historia vol.1, n. ${ }^{\circ}{ }^{2}$, México, Instituto Dr. José Luis Mora, 1995, pp.7-22.

Grieshaber, Erwin P., "Hacienda-Indian Community Relations and Indian Acculturation: An Historiographical Essay", in Latin American Research Review vol.XIV, n. ${ }^{\circ}$, Durham, University Duke Press, 1979, pp.107-128.

Guerra, Angélica, "Población y familia en Santiago de Jiutepec, alcaldía mayor de Cuernavaca, 1715-1793”, en América Molina del Villar y David Navarrete (coords.), Problemas demográficos vistos desde la historia. Análisis de fuentes, comportamientos y distribución de la población en México, siglos XVI-XIX, México, El Colegio de Michoacán/CIESAS, 2006, pp.157-198.

Herrera Casasús, María Luisa, Presencia y esclavitud del negro en la Huasteca, México, IIH/UAT/Miguel Ángel Porrúa, 1989.

Herrera Casasús, María Luisa, Misiones de la Huasteca potosina. La custodia del Salvador de Tampico época colonial, México, Programa de Desarrollo Cultura de la Huasteca/Instituto de Cultura de San Luis Potosí/CONACUlTA, 1999.

Kicza, John E., "The Social and Ethnic Historiography of Colonial Latin America: The Last Twenty Years", in William and Mary Quarterly vol.45, n. ${ }^{\circ} 3$, Virginia, Institute of Early American History and Culture, 1988, pp.453-488.

López de la Cámara, Alta Agustín, Descripción general de la nueva colonia de Santander, México, Imprenta "Beatriz de Silva", 1946 (Archivo de la Historia de Tamaulipas, $1^{\mathrm{a}}$. Serie, t. v). Compilado y editado por Gabriel Saldívar. 
Malvido, Elsa, "Factores de despoblación de reposición de la población de Cholula en la época colonial (1641-1810)”, en Elsa Malvido y Miguel Ángel Cuenya (Comps.), Demografía histórica de México: siglos XVI-XIX, México, Instituto Mora/UAM, 1993, pp.63-111, (Antologías Universitarias).

Mandeville, Peter B., La jurisdicción de la Villa de Santiago de los Valles en 170o-180o, San Luis Potosí, México, Academia de Historia Potosina, 1976 (Biblioteca de Historia Potosina, Serie Documentos 3).

McCaa, Robert, "Marriage, migration, and settling down: Parral (Nueva Vizcaya), 17701788", in David J Robinson (ed.), Migration in Colonial Spanish America, Cambridge, Cambridge University Press, 1990, pp.212-237.

Meade, Joaquín, Historia de Valles. Monografía de la Huasteca potosina, México, Sociedad Potosina de Estudios Históricos, San Luis Potosí, 1970.

Miño Grijalva, Manuel (coord.), La población de la ciudad de México en 179o: variables económicas y demográficas de una controversia, México, INEGI/COLMEX, 2002.

Molina del Villar, América, "Impacto de epidemias y crisis agrícola en comunidades indígenas y haciendas del México colonial, (1737-1742)”, en Virginia García Acosta, (coord.), Historia y desastres en América Latina, vol.I, México, La Red/CIESAS, 1996, pp.146-166.

Molina del Villar, América, La Nueva España y el matlazahuatl, 1736-1739, México, COLMICH/CIESAS, 2001.

Montejano y Aguiñaga, Rafael, El Valle del Maíz, S.L.P., $2^{\mathrm{a}}$. Edición, San Luis Potosí, México, UASLP, 2002.

Monroy de Martí, María Isabel, Pueblos, misiones y presidios de la intendencia de San Luis Potosí, San Luis Potosí, México, Archivo Histórico del Estado, 1991.

Mörner, Magnus, “The Spanish American Hacienda: A Survey of Recent Research and Debate", in Hispanic American Historical Review vol.53, n. ${ }^{\circ}$, Durham, Duke University Press, 1973, pp.183-216.

Mundy, Barbara E., The Mapping of New Spain. Indigenous Cartography and the Maps of the Relaciones Geográficas, Chicago, University of Chicago Press, 1996.

Naveda Adriana, "El censo de 1788, análisis poblacional de ranchos y haciendas en la Villa de Córdoba”, en Carmen Blázquez, Carlos Contreras y Sonia Pérez Toledo (coords.), Población y estructura Urbana en México, siglos XVIII y XIX, México, Instituto Mo- 
ra/Universidad Veracruzana/Universidad Autónoma Metropolitana, 1996, pp.111128.

Ouweneel, Arij, Ciclos interrumpidos. Ensayos sobre historia rural mexicana. Siglos XVIII-XIX, México, El Colegio Mexiquense, 1998.

Pastor, Rodolfo, “Introducción”, en Enrique Florescano (comp.), Fuentes para la historia de la crisis agrícola de 1785-1786, vol.I, México, AGN, 1981, pp.29-63.

Peniche Moreno, Paola, "Grupos de filiación y movilidad población. Los ch’ibales y la migración de los mayas en el siglo XVIII”, en Desacatos. Revista de Antropología Social n. ${ }^{\circ} 13$, México, CIESAS, 2003, pp.32-45.

Pérez Herrero, Pedro, "Evolución demográfica y estructura familias en México (17301850)”, en Familias novohispanas. Siglos XVI al XIX. Seminario de Historia de la Familia, México, COLMEX, 1994, pp.345-372.

Pérez Zevallos, Juan Manuel, "Las Visitas de la Huasteca (siglos XVI-XVIII)", en Jesús Ruvalcaba Mercado (coord.), Nuevos aportes al conocimiento de la Huasteca, México, CIESAS/CIHSLP/CEMCA/IPN/UACH/INI, 1998, pp.95-122.

Pérez Zevallos, Juan Manuel, "Fuentes para la historia de la movilidad de la población indígena en Nueva España”, en América Latina en la Historia Económica. Boletín de fuentes. Economía indígena n. ${ }^{\circ} 12$, México, Instituto de Investigaciones Dr. José María Luis Mora, 1999, pp.27-37.

Radding, Cynthia, Wandering Peoples. Colonialism, Ethnic Spaces, and Ecological Frontiers in Northwestern México, 1700-1850, Durham y Londres, Duke University Press, 1997.

Rangel Silva, José Alfredo, "Lo que antes era casa de Dios... Adaptaciones del liberalismo en los ámbitos locales, 1820-1825”, en Historia Mexicana vol.LIII, n. ${ }^{\circ} 1$, México, El Colegio de México, 2003, pp.117-178.

Rangel Silva, José Alfredo, Capitanes a guerra, linajes de frontera. Ascenso y consolidación de las élites, en el oriente de San Luis, 1617 - 1823, México, COLMEX, 2008.

Revilla Gigedo, Conde de, Informe sobre las Misiones -1743- e Instrucción Reservada al Marqués de Branciforte -1794-, México, Ed. Jus, 1966. Introducción y notas de José Bravo Ugarte.

Reyes Cotilla, Nora, "Conflicto étnico, poder local y recreación de la memoria de los pardos de Tamiahua”, en Juan Manuel Pérez Zevallos y Jesús Ruvalcaba Mercado 
(coords.), iViva la Huasteca! Jóvenes mirada sobre la región, México, CIESAS/COLSAN, 2003, pp.85-112. (Colección Huasteca)

Robinson, David J., "Introduction to Themes and Scales", in David J. Robinson (Ed.), Social Fabric and Spatial Structure in Colonial Latin America, Department of Geography, Syracuse University, 1979, pp.1-24.

Robinson, David J., "Introduction: towards a typology of migration in colonial Spanish America", in David J. Robinson (ed.), Migration in Colonial Spanish America, Cambridge, Cambridge University Press, 1990, pp.1-17.

Romero Navarrete, Lourdes y Echenique, Felipe, Relaciones geográficas de 1792, México, INAH, 1995 (Colección científica, serie historia).

Sahlins, Marshall, "Goodbye to Tristes Tropes: Ethnography in the Context of Modern World History", in Journal of Modern History vol.65, Chicago, University Chicago Press, 1993, pp.1-25.

Sánchez Santiró, Ernest, Padrón del Arzobispado de México, 1777, México, AGN, 2003.

Schröter, Bernd, "La frontera en hispanoamérica colonial: un estudio historiográfico comparativo", in Colonial Latin American Historical Review vol.10, n. ${ }^{\circ} 3$, Albuquerque, University of New Mexico, 2001, pp.351-385.

Seed, Patricia, Ceremonies of Possession in Europe's Conquest of the New World, 14921640, Cambridge, Cambridge University Press, 1998.

Solano, Francisco de (ed.), Cuestionarios para la formación de las Relaciones Geográficas de Indias. Siglos XVI/XIX, Madrid, Consejo Superior de Investigaciones CientíficasCentro de Estudios Históricos-Departamento de Historia de América, 1988 (Colección Tierra Nueva e Cielo Nuevo, núm. 25)

Spalding, Karen, "Social Climbers: Changing Patterns of Mobility among the Indians of Colonial Peru", in Hispanic American Historical Review vol.5o, n. ${ }^{\circ}$, Duke, Duke University Press, 1970, pp.645-664.

Sutter, Paul S., "The World with Us: The State of American Environmental History", in The Journal of American History vol.100, n. ${ }^{\circ}$, Bloomington, Organization of American Historians, 2013, pp.94-119.

Tanck de Estrada, Dorothy, Pueblos de indios y educación en el México colonial, 17501821, México, COLMEX, 1999. 
Tichy, Franz, "Pueblos, haciendas y ranchos en el área de Puebla-Tlaxcala", en Dalhgren Barbro (coord.), Mesoamérica. Homenaje al Dr. Paul Kirchhoff, México, SEP/INAH, 1979, pp.159-164.

Torre Villar, Ernesto de la, "Erección de obispados en el siglo XVIII. El obispado de Valles”, en Estudios de Historia Novohispana vol.3, México, Instituto de Investigaciones Históricas/UNAM, 1970, pp.173-234.

Uriega Ponce, de León Ángeles y Antonio Escobar Ohmstede, "La estructura socioeconómica de la jurisdicción de Tacaba en las postrimerías del siglo XVIII. El padrón militar de 1792", en Entorno Urbano. Revista de Historia vol.2, n. ${ }^{\circ} 3$, México, Instituto de Investigaciones Dr. José María Luis Mora/Universidad Veracruzana/Universidad Autónoma Metropolitana-Iztapalapa, 1996, pp.39-82.

Valdés Dávila, Carlos Manuel e Dávila del Bosque, Ildefonso, Los tlaxcaltecas en Coahuila, México, COLSAN/Gobierno del Estado de Tlaxcala, 1999.

Van Young, Eric, "La historia rural de México desde Chevalier: historiografía de la hacienda colonial”, en Historias n. ${ }^{\circ} 12$, México, Dirección de Estudios Históricos/INAH, 1986, pp.23-65.

Vetancurt, Agustín de, Teatro mexicano. Descripción breve de los sucesos ejemplares, históricos, políticos, militares y religiosos del Nuevo Mundo de las Indias, edición facsimilar, México, Ed. Porrúa, 1982 [1698].

Wood, Stephanie, “The Fundo Legal or Lands Por Razón de Pueblo: New Evidence from Central New Spain”, Arij Oweneel y Simon Miller (eds.), The Indian Community of Colonial Mexico. Fifteen Essays on Land Tenure, Corporate Organizations, Ideology and Village Politics, Amsterdam, CEDLA, 1990, pp.117-129 (CEDLA Latin America Studies, 58). 